Determining the Dynamics of HIV Voluntary Counselling and Testing Uptake among the Rural and Urban Communities of Nakuru District, Kenya.

By

Joseph Muchiri

\author{
A thesis \\ Submitted to Victoria University of Wellington \\ in fulfilment of the \\ Requirements for the degree of \\ Master of Arts \\ in Applied Social Science Research
}

School of Social and Cultural Studies

Victoria University of Wellington

2010 


\begin{abstract}
Globally, it is estimated that over 40 million people are living with HIV/AIDS with 67\% of these coming from Sub Sahara Africa. While the epidemic has been receiving increasing attention towards and more emphasis placed on access to care and treatment, these efforts are bound to become unsustainable due to a high rate of new infections. In 2007, for every HIV patient who was put on drugs six others became infected with the virus. Voluntary testing and counselling (VCT) has been suggested as the most effective intervention that could reverse this rate of infection. Its utilization in Africa and many parts of the world has however, been at an all time low. In Kenya where populations of over 1.4 million people are living with the HIV/AID virus, less than $20 \%$ of the total population knows their status. The aim of this study is, therefore, to establish and document the dynamics of VCT uptake in Nakuru district of Kenya with a view to suggesting measures to increase this uptake. The main objectives of the study were to identify factors that influence VCT uptake and determine the levels of knowledge and prevailing attitudes on HIV testing. The role that gender plays in VCT utilization was also explored.
\end{abstract}

This was a cross sectional study in which a mixed research method methodology employing quantitative and qualitative data collection methods was used. Quantitative data was collected using a structured questionnaire while qualitative data was collected using focus group discussions and key informant interviews. The target population was residents of Nakuru aged 16-60. 480 distributed completed the structured questionnaire out which 422 were completed and returned. Six focus group discussions and five key informant interviews were carried out.

The research found that the awareness regarding HIV and VCT among the community members is relatively high. However, there are still a significant proportion of people who hold misconceptions about the disease and the testing service. This may partially explain why people opted not to take the test for the virus. Further, a majority of the people wanted to take up the test but both social and health system barriers such as gender inequality, the cost of taking the service, service operational hours, accessibility; misconceptions about the disease are barriers to the utilization of the service. The study recommends the adoption of more pro-active model of testing which could include mobile and home-based testing to help remove most of these barriers and therefore lead to an increased uptake. Moreover promotional activities targeting couples, providing the service beyond the current normal working hours weekdays and weekends, strengthening the general public health facility to 
help win back the trust of the service consumer and provision of youth-friendly voluntary counselling and testing for HIV (VCT) service are recommended. 


\section{Acknowledgements}

This study has been both academically and personally challenging and I am grateful to a number of people for their continued assistance throughout this project. Firstly, I would like to thank my supervisor Prof Kevin Dew for his continued guidance and support throughout the development and completion of this study. Thank you also to the staff at the School of Social and Cultural Studies for their assistance.

I would like to thank the National AIDS and STI Control Programme for the assistance in conducting this research. In particular, heartfelt thanks to the Nakuru District AIDS and STI Control Programme Coordinator who was instrumental in organizing all the key informant interviews for me; and to Faulu Kenya who facilitated my FGDS.

There are also a number of others who have supported my research. I would sincerely like to thank my wife Jenifer and son Brian for your Moral Support; you listened to me even when I did not make sense. Mr Titus Wahome for his valued inputs. To NZAID, for their financial support throughout my stay at the University. Finally, thank you to all those who accepted to be my respondents and gave up time from their busy schedules to speak to me. Many thanks for sharing your experiences and opinions so freely and honestly. 


\section{Table of Ccontent}

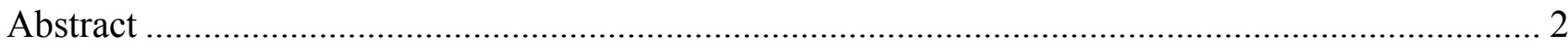

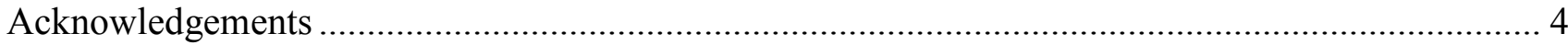

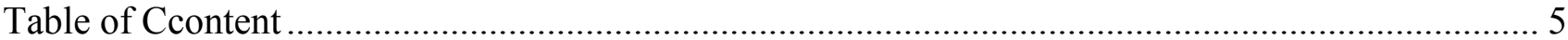

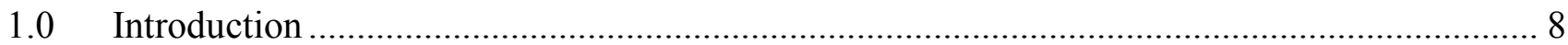

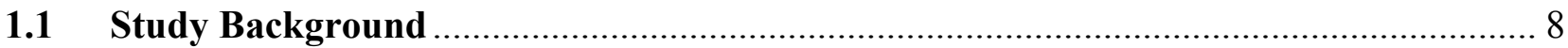

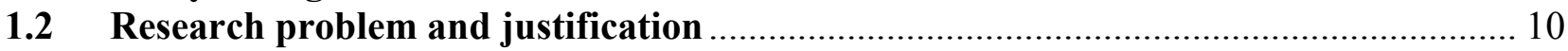

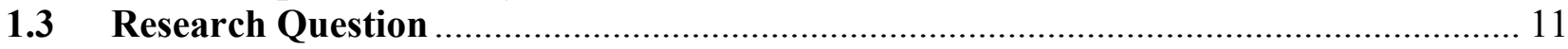

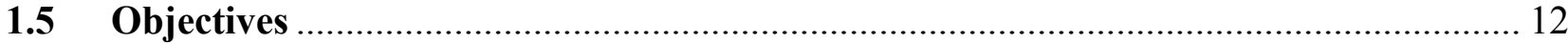

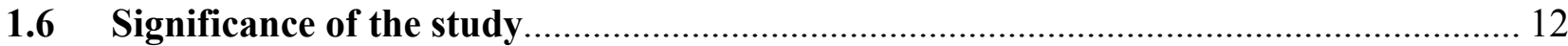

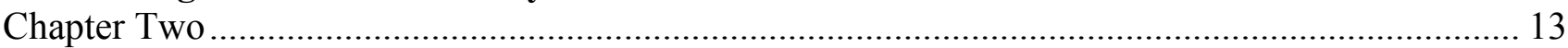

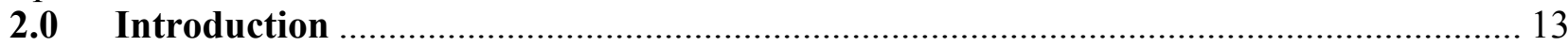

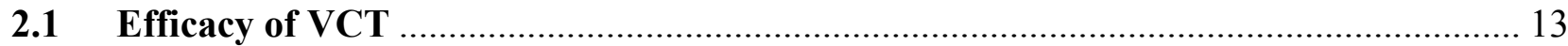

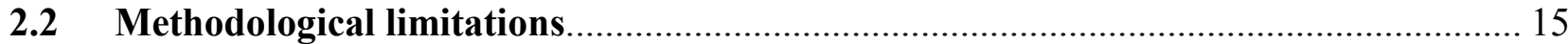

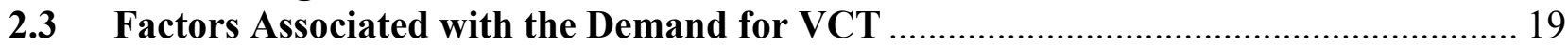

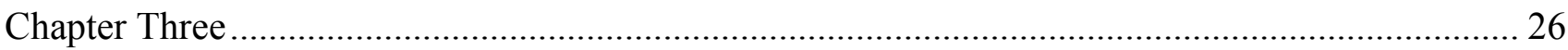

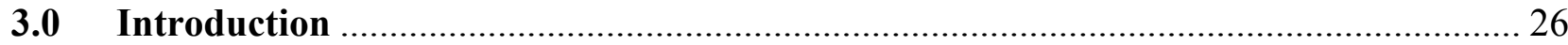

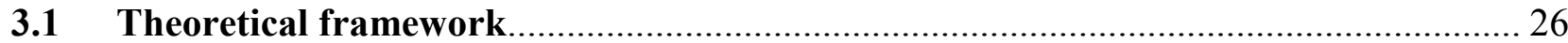

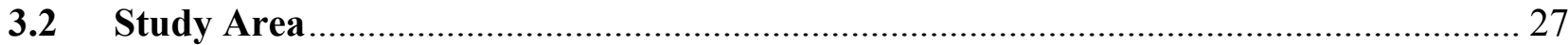

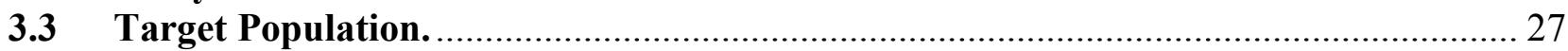

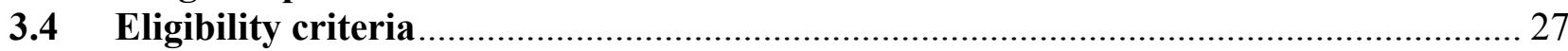

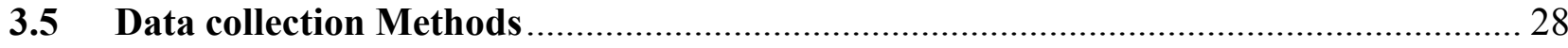

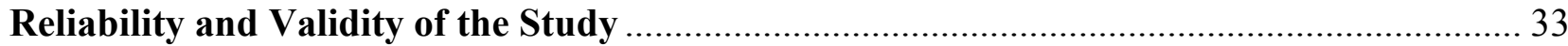

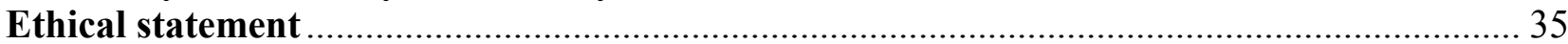

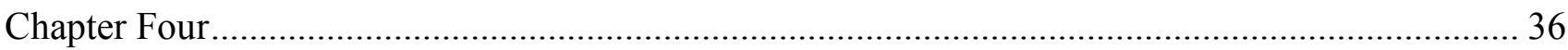

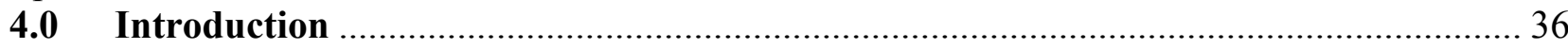

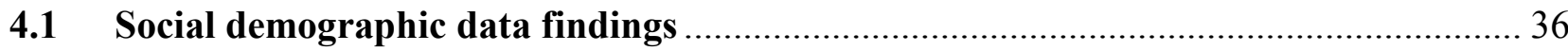

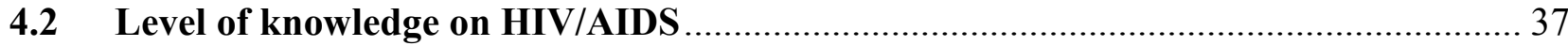

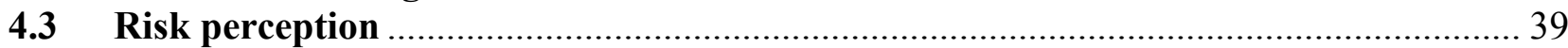

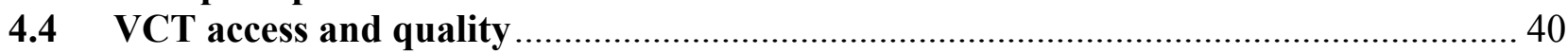

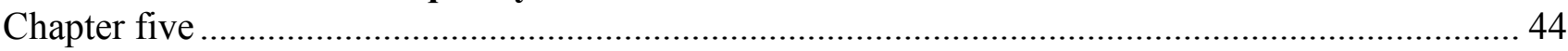

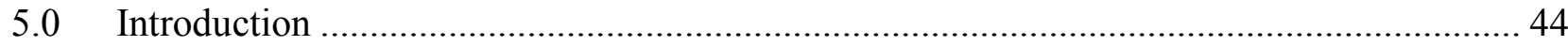

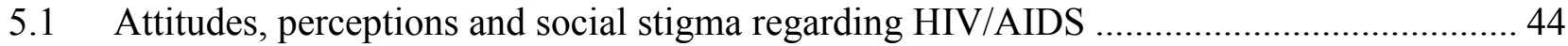

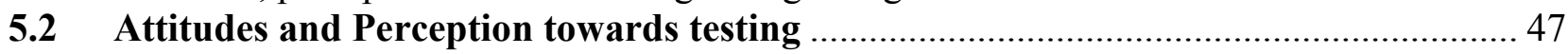

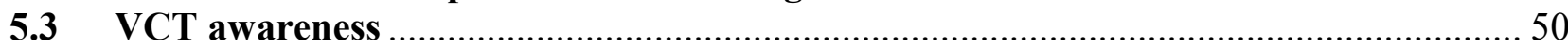

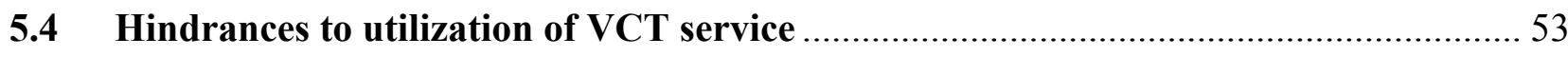

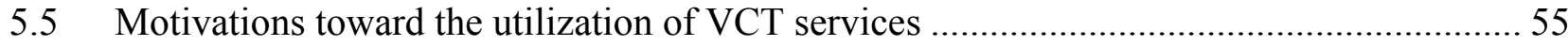

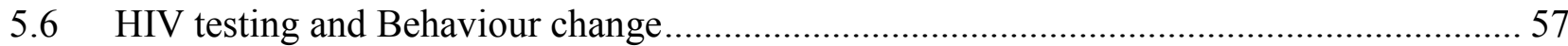

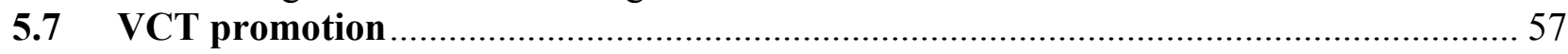

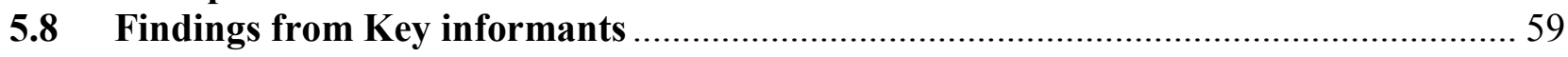

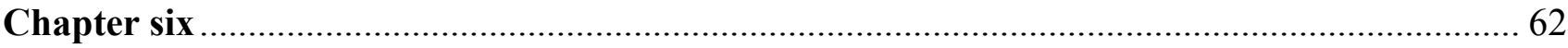

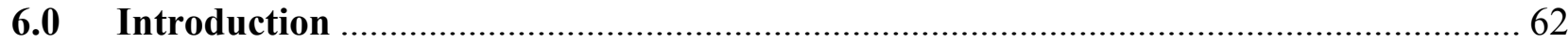

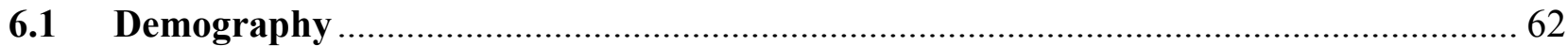

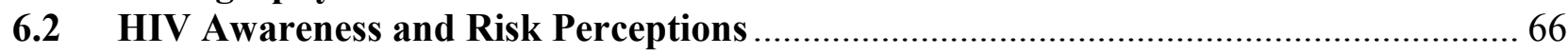

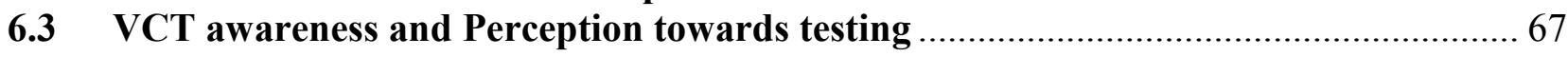

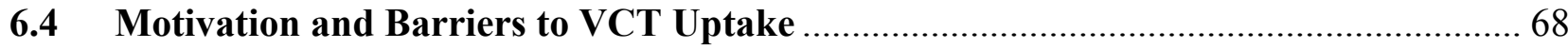




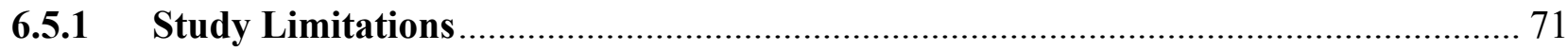

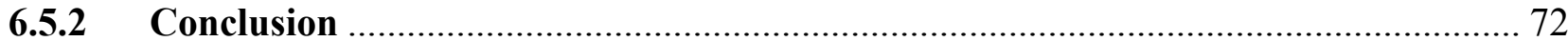

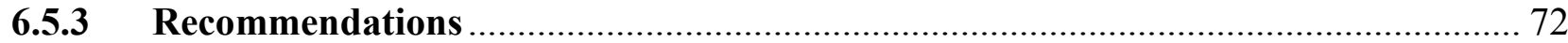

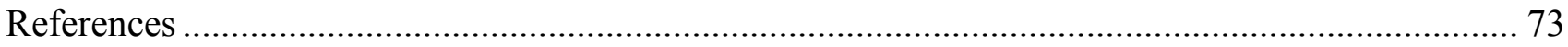

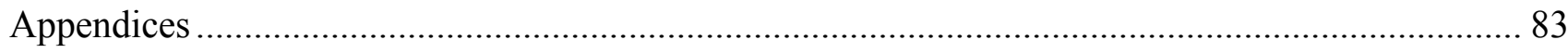




\subsection{Introduction}

\section{Chapter One}

This chapter presents the background of the study. The chapter begins by presenting background information upon which the study was undertaken after which the research problem is outlined. It ends by presenting the research questions, and objectives

\subsection{Study Background}

In more than 20 years HIV/AIDS has become the worst medical catastrophe ever experienced by humankind. Globally it is estimated that over 40 million people are living with HIV/AIDS, with its impact likely to be felt for generations to come. Sub-Saharan Africa remains the region most heavily affected by HIV/AIDS accounting for $67 \%$ of all people living with HIV and $75 \%$ of AIDS deaths in 2007 (UNAIDS 2008).

In those countries heavily affected, HIV has reduced life expectancy by more than 20 years, lowered economic growth, and deepened household poverty. In sub-Saharan Africa alone, the epidemic has orphaned nearly 12 million children aged under 18 years. The natural age distribution in many national populations in sub-Saharan Africa has been dramatically skewed by HIV, with potentially perilous consequences for the transfer of knowledge and values from one generation to the next (Global HIV working group, 2007).

In 2007, more than 1.4 million Kenyans were living with HIV/AIDS; with the biggest proportion of this affecting Kenyans aged between 30-34 years compared to other age categories. Further, the burden of infections is reported to be higher among females than males up until age 35 after which the ratio of male to female infections starts to approach 1 to 1(NASCOP, 2008). Moreover, between 2003-2007 the prevalence of HIV in rural Kenya is reported to have increased by 58\%. Forty five percent of these new infections are reported to have occurred among married or cohabitating couples (NASCOP, 2008).

While increased attention has been paid to HIV epidemic with more emphasis placed on access to care and treatment, efforts to reduce HIV incidence are faltering. For example, for every patient who initiated antiretroviral therapy in 2006, six other individuals became infected with HIV (Global HIV working group, 2007). If the current trends continue, it is projected that 60 million more HIV infections will occur by 2015 , and the annual number of new HIV infections will increase by $20 \%$ or 
more by 2012. However, if comprehensive HIV prevention were up scaled scale, projections show that half of new infections projected to occur by 2015 could be averted. In sub-Saharan Africa alone, for example $52 \%$ of projected infections could be prevented and the annual number of new HIV infections could be reduced by nearly two-thirds to fewer than 2 million infections by 2015 (Global HIV Prevention Working Group 2007).

One intervention that has been advocated for is the use of voluntary counselling and testing. Voluntary counselling and Testing (VCT) is the process by which an individual undergoes counselling to enable him/her to make informed choices about being tested for HIV. In Kenya the service is offered free of charge by the government and Non-governmental organizations. The procedure of taking the test is such that clients who want to know their HIV status make an appointment to see the counsellor in advance. On the due date pre-test counselling is done, a process that involves giving information about the test and preparing the client for to receive the test results. Following this, if the client wants to continue with the test, a blood sample is taken and the test is done. In Kenya the Enzyme immunoassay (EIA) test is generally used and is confirmed using Western blot test. The procedure then ends with post-test counseling, which is a dialogue between the client and a care provider, aimed at discussing the HIV test result, providing appropriate information, support and referral, and encouraging risk reduction behaviours.

Underlying the offering of this service are two assumptions: first, that after being tested and learning of HIV results, individuals positively change their sexual behaviour. The second assumption is that people want to know their HIV status and would utilize services if they were provided inexpensively. 


\subsection{Research problem and justification}

When the Government of Kenya declared HIV/AIDS a national disaster in 1999, VCT centers were introduced as an intervention strategy to combat the pandemic. These centers are places where individuals who may want to know their HIV status can voluntarily go for free service. The overall objective of VCT service is to help decrease anxiety, stigma, fear, and the sense of hopelessness associated with HIV testing (MOH, 1999).

According to Kenya's Ministry of Health, less than 20 per cent of Kenyans know their HIV status at the moment and there is an estimated 1.2 million HIV-infected Kenyans who do not know that they carry the virus (NASCOP, 2008). In the Kenya Demographic Health Survey (KDHS) conducted in 2003, 67 percent of the respondents indicated that they would have liked to take a HIV test (CBS, 2003). In response to the findings the Government increased the number of VCT centers and allocated more staff and resources to these. Despite this development, a recent study by Ngatia et al, (2007) showed the VCT uptake level still low. This study therefore seeks to determine the dynamics of VCT uptake among the sexually active Kenyan aged 15 -34 years.

The current researcher is an employee at the Health of Migrant population project (HMP), School of Medicine, Moi University, Kenya. My interest in this area has come through my interaction with HIV patients during the course of my work particularly a project that monitored adherence to antiretroviral drugs among the HIV patients attending clinics at the Moi Teaching and Referral Hospital Kenya. I realized that the majority of the patients learned they were infected with HIV when it was too late, when the disease had progressed to advanced stages making its management very difficult. It is my hope that the findings of this study will re-energize efforts aimed at increasing VCT service uptake by the Kenya government and other stake holders in the fight against HIV/AIDS.

There are several justifications for carrying out this study. Firstly, Voluntary counselling and Testing is an essential component of an effective response to the AIDS pandemic in that it targets behavior change. Knowing one's HIV status empowers people to make informed decisions about their sexual lifestyles that would otherwise predispose individuals to HIV infection. It has also been 
hypothesized that in mature epidemics where death due to HIV is common, people who test HIV sero-negative will jealously guard their HIV negative sero-status (Global HIV working group, 2007).

Secondly, VCT is a crucial step towards the use of antiretroviral therapy that greatly improves the quality of life among HIV infected persons. Furthermore, research in many countries has shown that people who know their sero-status, whether it is HIV negative or positive, drastically change their behaviour (UNAIDS, 2001). One of the major government strategies is to make voluntary counselling and testing services widely available, so as to target the majority of the population not yet infected and to encourage early identification of those who are infected so that they can access proper care services.

The final justification of carrying out this study has to do with the methodology used in the previous studies reviewed. The majority of the studies reviewed have used people who have already volunteered to go for the test as their target population. There are a number of problems with this approach, firstly, in using those who volunteered for VCT, a strong self-selection bias is created - a bias that is especially problematic as there is good reason to suspect that those who volunteer for VCT are already fundamentally different to those who do not. It is highly probable that these volunteers are far more sexually responsible and at lower risk of HIV infection in the first place. It would therefore appear that targeting both service users and non service users would yield more insight on factors influencing its uptake. Moreover, the use of a mixed method methodology allows the researcher to go deeper on issues of voluntary counselling and testing uptake as opposed to use of quantitative methodology alone which is common among the existing studies reviewed.

\subsection{Research Question}

The study research question is 'What factors influence utilization of VCT centers among sexually active Kenyans aged 18-60 years?'

\section{$1.4 \quad$ Aim}

The aim of this study is to establish and document determinants of VCT uptake in Nakuru district with a view to indentifying measures to increase uptake. 


\subsection{Objectives}

The objectives of the study are:

1 To determine factors that influence VCT uptake.

2 To determine the levels of knowledge and prevailing attitudes on HIV testing among Nakuru residents aged between 18 years and above

3 To establish the role that gender plays in VCT utilization.

\subsection{Significance of the study}

While many studies have been done in this area, this study will increase our knowledge on what motivates an individual to make a decision to utilize a service. This is crucial especially in policymaking. Poor or unfavorable operational policies have been mentioned as largely responsible for the low coverage of essential services in low and middle income countries. This is because laws and policies alone do not guarantee effective and balanced programs for prevention, care, treatment and mitigation of the impact of HIV/AIDS. A legal and policy framework that takes into account the local context is fundamental for governments to orient and coordinate a coherent national response and mobilize needed internal and international resources. 


\section{Chapter Two}

\section{Literature Review}

\subsection{Introduction}

This chapter provides the literature review. The chapter begins with reviewing literature on the efficacy of VCT in preventing HIV AIDS after which the methodological limitations of the studies reviewed is presented. The chapter ends by reviewing studies touching on factors that influences VCT uptake.

\section{$2.1 \quad$ Efficacy of VCT}

In a review of literature on the efficacy of VCT for achieving prevention goals, two main preventative outcomes have been addressed; this includes the efficacy of VCT in achieving primary prevention, i.e. facilitating behaviour change in those who test negative, and the efficacy of VCT in achieving secondary prevention, i.e. facilitating behaviour change in those who test positive. Most investigations into these two areas, conducted in Western contexts, point to the efficacy of VCT for achieving secondary prevention goals, although it does not appear to be an effective means of primary prevention (Wilson, Levinson, Jaccard, Minkoff \& Endias, 1996, Landis, Earp \& Koch, 1992, Ickovics, Morrill, Beren, Walsh \& Rodin, 1994).

Nevertheless, recent studies conducted in Africa provide evidence of some reduction in self-reported risk behaviors following VCT service utilization. Further, literature shows two common findings. The first one is that risk-reducing behaviour change tends to be larger among individuals who test positive than among those who test negative (Allen, Serufilira, et al. 1992; VCT Efficacy Study Group 2000a; van der Straten et al. 1995; Lutalo, Kidugavu, and Wawer 2000).

The second common finding is that counselling of couples and/or partner testing appears to be an effective technique for altering risky sexual behavior as well. Couple counselling has also been shown to be more effective than individual testing and counselling when the two are compared (Allen, Serufilira, et al. 1992; Allen, Tice, et al. 1992; van der Straten et al. 1995; Kamenga et al. 1991; Study Group 2000a). In particular, the counselling of sero-discordant partners (one HIV positive, the other negative) who test together has been shown to adjust their behaviors. Seventyseven percent of Kamenga et al.'s (1991) sample of sero-discordant couples reported using condoms during all episodes of sexual intercourse 18 months after testing and counselling, compared with 5\% 
before counselling. It is not clear if these outcomes occur because couples counselling provides a means for broaching this difficult subjects between partners.

Findings that VCT does not appear to facilitate preventative behaviour change in sero-negative individuals is confounded by the fact that increased condom-use, which is often used to measure behaviour change, may not be an appropriate outcome measure for sero-negative individuals. This is because many individuals use VCT testing (or repeat HIV testing) to establish sero-status at the outset of a new monogamous relationship, with the implicit intention of ceasing condom-use. A study conducted in Uganda, revealed that $27 \%$ of participants were taking a HIV test because of a planned marriage or a new relationship. This was even more common in the case of couples coming for VCT where $84 \%$ were planning a new marriage/relationship (Muller et al, 1992). When asked about behaviour change in response to a negative test result, the most common reported intentions were marriage $(81 \%)$ followed by monogamy $(17 \%)$. The use of condoms was only mentioned by $2 \%$ of respondents. This finding may well reflect the focus of the previous AIDS education campaign in Uganda, in which condom-use was de-emphasized.

However, the fact remains that in these cases, VCT clearly functions as 'a form of technological solution' to the problem of safer sex (Watney, 1990; in Beardsell, 1994). While this may be a rational strategy for monogamous couples, it has nonetheless been argued on the basis of such research that VCT may be counterproductive in so far as individuals then proceed to have unprotected sex (Wilson et al, 1992). Clearly, perceptions of low susceptibility may be reinforced by a negative test result.

Overall recent research gives an impression that VCT leads to reduced risk behaviors among certain types of tester, that is, HIV-positive individuals and couples, particularly sero-discordant ones. The literature offers less reason for optimism about those who test HIV negative. These findings suggest that VCT has a potential to make significant impact on the epidemic but only if it is able to attract large numbers of HIV-positive individuals, particularly those who are not yet ill and sexually active.

It is questionable however, whether any of these conclusions and recommendations about the preventative efficacy of VCT should be drawn from the body of literature reviewed here. This literature contains numerous methodological and conceptual limitations, making any claims of 
efficacy highly dubious, and making it all but impossible to make any clear-cut policy recommendations.

\subsection{Methodological limitations}

A main methodological limitation of those studies looking at the efficacy of VCT for achieving prevention goals is that most of these studies did not constitute randomized controlled clinical trials with the result that efficacy becomes extremely difficult to establish. Instead, as a result of the ethical requirements attached to the provision of VCT to anyone who requests it, the efficacy trials were forced to select a sample from those who had already requested HIV counselling and testing; using either the rate of sero-conversion in the general population (Muller et al, 1992), those who had not requested VCT, or those individuals who had received some other intervention (Coates et al, 2000) as a comparison group.

There are a number of problems with this approach, firstly, in using those who volunteered for VCT, a strong self-selection bias is created - a bias that is especially problematic as there is a good reason to suspect that those who volunteer for VCT are already fundamentally different to those who do not. It is highly probable that these volunteers are far more sexually responsible and at lower risk of HIV infection in the first place. This self-selection bias is further compounded by the fact that participants must not only volunteer for VCT, but also for the research study and follow-up ( Higgings, 1991, In Beardsell, 1994).

Due to this self-selection bias, the two groups that are chosen for comparison (i.e. VCT and nonVCT) cannot be said to be similar along a number of important base-line characteristics, e.g. sexual behavior, condom-usage etc. This is an important problem for any efficacy study, as it means that any behavior changes that occur in the intervention group cannot be attributed to the VCT process; such changes could be as a result of the differences between the groups. In fact, well-controlled studies show that those who come forward for testing may have been motivated to make behavioral changes before the testing even took place, with the result that VCT did not, in fact, cause the behavior change. For example, a study in South Africa (Abdool Karim, Hoosen \& Susser, 1998) showed that when a baseline survey was conducted, VCT did not alter or increase participant's reported intentions to practice safer sex. The authors found that this was because both before and 
after VCT, almost all women stated that they intended to use condoms and reduce the number of their partners.

A second methodological limitation with the VCT efficacy studies is that efficacy is commonly measured in terms of only two behavioral outcomes, i.e. reported condom use and rates of seroconversion. However, in an effort to establish the efficacy of VCT, researchers have tended to ignore the obvious: that outcome measures based on sexual behavior are both unreliable and inappropriate. This is for three main reasons: first, that VCT in and of itself, is unlikely to, and cannot be expected to, re-arrange human sexual behavior. There is no proven relationship between VCT and sexual behavior. On the other hand, research that proves that such a relationship does not exist cannot conclude that VCT is a waste of time or resources since the prevention effect of VCT, in combination with other interventions and under certain conditions, may be substantial. Secondly, self-reported behavior change cannot be relied upon; behavioral measures, which are retrospectively self-reported, are biased by both recall and perceived social desirability. And finally, to measure the success of a client-centered counselling approach against predefined objectives, as opposed to the client's expectations and needs, is contradictory in that one function of counselling is to inform the client so that they can make informed choice. The idea that specific behavioral outcomes are produced by VCT is in conflict with the goals and aims of counselling.

A third methodological limitation is that in the studies reviewed the process of VCT has not been well defined, with the result that there are important differences across the studies in terms of key aspects of VCT (e.g. length and/or number of counselling sessions). In general, these studies provide little detail about the actual counselling procedures used, and even where standard guidelines for counselling are provided, there is little recognition of the fact that Counsellors may disregard these guidelines and/or interpret them differently.

The main problem with these differences is fairly obvious, i.e. if the stimulus of VCT is not uniform, efficacy studies evaluating "VCT" may all be evaluating different things. Efficacy outcomes may have more to do with the type and/or standard of counselling, or the personalities or objectives of Counsellors themselves, than any other factor. The impact that different types of counselling or Counsellors can have on the VCT process has been demonstrated in some detail in qualitative 
research by both Silverman (1989) and Stein (2001). In addition, quantitative studies have shown that there are considerable variations in the proportions of clients who decide to proceed with testing after counselling depending on the differences in location and/or Counsellor characteristics (Beardsell and Coyle, 1996).

In the studies reviewed, equally little attention is given to the context of VCT and how this may have influenced study findings. Multiple social, economic and cultural factors, too numerous to list let alone measure, may interact with counselling to affect behaviour. For example, participant characteristics moderating the effectiveness of VCT have not, and indeed cannot be, adequately controlled. Studies reviewed have attempted to ascertain the impact of participant characteristics in terms of demographic and crude psychosocial categories such as gender, income and education. Unsurprisingly, such studies show inconsistent findings.

Motivation to change on the part of the individual appears to be an uncontrolled factor for all relevant studies reviewed with the exception of Abdool Karim et al (1991). Clearly, change is dependent upon motivation and the pre-existence of motivation to change, or lack thereof, will influence behavioral outcomes. While there is increasing evidence that motivation to change is not necessarily a good predictor of any behavior, especially sexual behavior, the fact remains that many of the investigations in this review conducted their studies in contexts such as ante-natal and STI clinics. In these settings, VCT is routinely promoted to all clients, making VCT less of a personal choice than a routine mandated testing procedure. It seems likely therefore, that a sample of clients from the general population actively seeking VCT, rather than those having the service recommended to them by authority figures such as nursing personnel, may yield very different findings.

Taking into account these methodological limitations, a number of recommendations for future research can be made. Firstly, it is clear that if we want to establish the efficacy of VCT for achieving preventative outcomes, more randomized trials are needed. Researcher need to come up with methods that address ethical issues related to randomization to allow control for extraneous factors. Moreover, these studies need to better address the methodological limitations discussed above - especially the issue of establishing better outcome indicators for VCT. 
However, the variability that exists across study findings as to the efficacy of VCT for achieving either primary or secondary prevention goals raises the issue of whether exploring issues of efficacy is the right question for VCT research in African settings. Rather, it could be that the question that needs to be explored in this field is not so much whether VCT is effective for primary or secondary prevention in African contexts, but rather, under what specific conditions it is effective and this is the main subject of the current study. Clearly, disclosure to partners is one of the determining variables in this regard. In the absence of disclosure to partners, participant's sexual behaviour depends as much and in the case of women, arguably more, on the attitudes and intentions of their partners as on their own attitudes and intentions regarding safer sex. This could prove to be an important area for future research.

Moreover, it is clear that even if available outcome evaluation data does provide valid, albeit inconsistent evidence as to the effects of $\mathrm{VCT}$ on prevention, rather than what has been referred to as 'spurious statistical links', they nonetheless provide little information as to how and why such outcomes, negative or positive, were achieved. For this reason, some authors advocate a move away from outcomes based research, which they claim, contributes nothing to the generation of theory relevant to VCT because such research neither identifies nor describes the factors leading to specific outcomes. These authors therefore support the idea that resources be dedicated to more qualitative process-based research which can identify the reasons why any given service is succeeding or failing. Only such research can provide an informed basis for amending and developing services (Beardsell and Coyle, 1996).

One qualitative study reviewed (Meursing, 1999) is an example of the way in which process-based research can provide valuable information regarding the behavioral outcomes under review. In this study, counsellors recorded all their sessions, thus creating a highly detailed record of client's problems and coping strategies over time. The findings of this research showed that HIV positive individuals did not succeed in maintaining long-term, consistent condom-use citing factors such as lack of hope based on respondents misinformation about HIV, fear of stigma, psychological avoidance whereby on symptoms improvement, many HIV people pushed thoughts of their HIV status aside or even began to believe that they were cured which decreased the motivation for condom use, lack of co-operation from the partner whereby women cited lack of cooperation of their husband; and fertility concerns. 
It seems surprising that only one study in this review made use of counsellors own obvious capacity to elicit detailed contextualized data within counselling sessions which has obvious potential for challenging existing theories and generating new ones. It seems likely that this is because such 'casehistory' methodologies do not approximate the scientific ideals of verification and generalisability. These values, despite the fact that they are arguably outdated and inappropriate, remain the guiding principals in defining research design and determining what research findings are published. As Beardsell \& Coyle (1996) point out, this is despite the fact that quantitative studies seldom produce findings that can contribute to the framing of policy or the development of counselling practice. Additional qualitative research is urgently required regarding all aspects of the actual counselling

and testing process, including the way in which informed consent is obtained, risk is assessed and risk reduction strategies developed, and the way that results are given to clients. The value of supplementary research to contextualise efficacy study findings cannot be over-emphasised in terms of their insights into what it means to do effective VCT, what factors influence the efficacy of VCT and how these can translate into the development of better VCT programmes.

\subsection{Factors Associated with the Demand for VCT}

\section{Attitudes towards VCT}

Studies that have focused on people's attitudes to VCT, in general, attempt to provide some measure of the acceptability of VCT in some population as an indicator of the demand for VCT services in that population. Such studies have shown high acceptance of VCT programmes, and HIV prevention services in general across a number of countries, including Abidjan, Kenya, Tanzania, Malawi, Zambia and Zimbabwe (Cartoux, Meda, Van de Perre, Newell, de Vincentzi, Dabis \& The Ghent International Working Group on Mother-To-Child Transmission of HIV, 1998; Cartoux, Msellati, Meda, Welffens-Ekra, Mandelbrot, Leroy, Van de Perre,P \& Dabis, 1998, Kiarie, Nduati, Koigi, Musia \& John, 1999, Kipp et al, 2001, Pool, Nyanzi, Whitworth, 2001, Wilkinson and Wilkenson, 2001).

However, the value of using acceptability as a measure of the demand for VCT services is somewhat questionable. A high level of acceptance at the level of attitudes, and a stated desirability for a service is not always equal to the intention to use it. Likewise, a stated intention to test is not equivalent to, but only a precondition for, undergoing the process of VCT. This is shown not only in the fact that there are low levels of HIV testing in areas where there is high acceptability and demand 
for VCT services, but also in the fact that even those who do come for testing and counselling do not always return for their results, showing that willingness to test does not always equal willingness to know. This point is well demonstrated by Fylkesnes, Haworth, Rosensvard and Kwapa (1999).

These researchers explored the uptake of VCT in a general population sample of selected urban and rural areas of Zambia. Of those stating that they wanted testing only $9.4 \%$ actually came forward to be tested. Furthermore, less than half of those who did get tested returned for their test results. These authors found that although self-perceived risk and high-risk behaviours were positively associated with initial (in principal) willingness to test, they were not associated with the actual use of VCT services, demonstrating that the use of VCT services may be predicated on far more complicated factors than attitudes towards these services. A more appropriate measure of the extent to which VCT is actually deemed desirable in any given population, may be the extent to which participants who undergo VCT return for their test results. Certainly, if counselling accompanies testing, then this is because it is generally acknowledged that only after a process of counselling are individuals in a position to make informed decisions regarding whether or not they want to undergo testing. Thus, in measuring the extent to which people make this informed decision, one should have a better indicator of the actual willingness to test in a population. Studies that have used return rates as an indicator, have on the whole found low rates of return for test results (Ladner et al, 1996, Sahly, Kassa, Agonafer, Tsegaye, De Wit, Gebremarium, Doorly, Spijkerman, Yeneneh, Coutinho \& Fontanet, 1999, Kip et al, 2001). For example, in a study conducted in Ethiopia less than half (43.5\%) of those who came for VCT returned for post-test counselling and their results (Sahlu et al 1999, 127).

Similarly, a study conducted in Nairobi found that only $35 \%$ of women choose to return for their results (Temmerman et al, 1995). Other studies show less extreme, but still significant dropout rates (Ladner et al, 1996 Cartoux, Msellati, Meda, Welffens-Ekra, Mandelbrot, Leroy, Van de Perre \& Dabis, 1998, Sahly et al, 1999, Kiarie, Nduati, Koigi, Musia \& John, 2000. Kipp et al, 2001). This issue may, at first sight, appear to have lost much of its urgency with the advent of rapid testing. It has been demonstrated that uptake rates, i.e. the proportion of those returning for post-test counselling and receiving their results) can be improved significantly by simply shortening the period of time between pre and post-test counselling (Fylkesnes et al, 1999). However, findings regarding return rates are still very important, in so far as they indicate that people who request their 
blood to be taken often change their mind if given the opportunity to do so. This should clearly be taken into account in the refinement of counselling procedures applicable to rapid testing protocols to ensure that those receiving testing really do want to know their HIV status.

It seems likely that high-drop out rates can be attributed to counselling procedure as much as to individual or group variables. In other words, it is possible that the approach to, and method of, pretest counselling used, is a determining factor of the extent to which individuals, especially high-risk individuals, return for their results. For example, in a London Health District, where high-risk patients were individually counselled for between 20 and 40 minutes, all of those who decided to undergo testing returned to receive their results (Bor, Miller \& Salt, 1991). By comparison, in many of the African studies under review, pretest counselling was performed through group pre-test, followed by individual post-test counselling. It is clear that those who are part of this group pre-test session (e.g. women at ante-natal clinics) may feel pressured to "consent" to testing and it is therefore unsurprising that many of these people fail to return for their results.

This pressure to "consent" for testing may be especially true of VCT efficacy trials and other research studies where participants may be tested not to know their status but for a myriad of other factors. For example, in the efficacy study in rural Uganda where there were extremely high drop out rates for post-test counselling, $74 \%$ of participants said that they underwent HIV testing not because they wanted to know their results, but because they wanted to be part of another research study (Kipp et al, 2001). Similarly, in a study of informed consent in VCT research, Abdool Karim et al. (1998) found that although women participating were assured that their participation was voluntary, and indeed, participants themselves stated that they 'wanted to know' their HIV status, $88 \%$ also maintained that they felt compelled to participate in the research. Of these, $28 \%$ stated that they agreed to the test in order not to compromise the care they had come to the hospital for in the first place. This subtle coercive element - which may operate in any research conducted at public health care settings or where health care professionals are held in high regard - has already been noted by other researchers (Strode, 2009). It is well documented that patients relinquish autonomy to professional medical authority in medical settings and it is therefore not surprising that informed consent sought under such circumstances may be less than voluntary. In such contexts, not returning for test results may be the only polite way for many women to decline testing. 
These findings reinforce the concern of Fylkesnes et al (1999) that the use of rapid testing in contexts such as STI clinics, antenatal clinics and TB clinics - where VCT is routinely offered to all clients needs to be further examined. The promotion of VCT to all clients is very different to a situation where VCT service is simply made available to those who may request it. While the anxiety attendant upon waiting for results is significantly reduced with the advent of rapid testing, the client is given only limited time to reflect on the pre-test and to make a considered decision about whether they really wish to proceed with the testing procedure (Beardsell and Coyle, 1996). Clearly, rapid testing highlights the difficulties inherent in achieving genuine and well-considered informed consent. The implications for counsellors as well as clients must be considered if many of those who might well have chosen not to return for their results, are in fact not truly willing to entertain a positive result, yet will now be receiving it.

\section{Perceived Vulnerability}

Many studies have shown that the one variable most significantly associated with failure to return for post-test counselling and results is the perceived probability of a positive HIV test result (Wilson et al, 1996). This is despite a widely held view that an awareness of risk is one of the primary motivators for individuals to get tested in the first place (Maman et al, 2001). For example, Cartoux et al. (1998) show that HIV-infected women in Burkina Faso, West Africa, were three times less likely to return for results than uninfected women. Similarly, Temmerman et al. (1995) show that only $35 \%$ of women with a positive test result at an ante-natal clinic in Ethiopia requested their results (Ladner et al, 1996 and Kiarie et al, 1999) report similar findings). This suggests that those who are willing to receive a test result are doing so because they have reason to believe that it will be negative. For this reason, Manson (1990, as cited in Beardsell, 1994) argues: "people who are unlikely to be infected are the ones who take the test, in droves".

Certainly, there has been a great deal of resistance to VCT in African settings on the grounds that confidentiality procedures may not be trusted, and that stigmatization and discrimination results from disclosure. In addition, it has been acknowledged that knowledge of sero-status increases anxiety without major treatment benefits in low-income countries where antiretroviral therapy is not universally available (Ladner et al, 1996, Van Rooyen \& Wood, 1998, Kipp et al, 2001). Such concerns may well outweigh the advantages of receiving a test result; especially for those who have reason to believe their result may be positive. 
However, findings regarding the extent to which HIV-positive as opposed to HIV-negative people volunteer for VCT are not wholly conclusive. In Northern Uganda, differentials in attitudes towards HIV tests showed that ethnicity, marital status and gender, but not HIV status, were some of the determinants of willingness to be tested (Ayiga, Ntozi, Ahimbisibwe, Odwee \& Okurut, 1999). Likewise, In Ethiopia, (Sahly et al, 1999) factors affecting post-test attendance did not include HIV status and results were requested equally often by sero-positive and sero-negative women; however these authors did suggest that this population may not have recognized themselves to be at risk.

What is clear, however, is that the assumption that perceptions of personal risk or perceived vulnerability will motivate individuals to be tested is an erroneous one. Two studies specifically investigated this question and found that previous high-risk behaviour was not significantly associated with the decision to test (Sahly et al, 1999, Machekano, Mcfarland, Mbizvo, Bassett, Katzenstein \& Latif, 1998,). In fact, males who reported recent casual partners tended to be more reluctant to learn their test results. This could be attributed to the psychological factors of denial and avoidance coping (i.e. not wanting to know) on the part of those who know they are at high risk of being infected (Wilson et al, 1996).

Other research findings show that the relation between perceived risk, actual risk and HIV test results is an exceptionally complicated one. For example, Wilson et al. (1996) have shown that self-reported previous risk is not significantly associated with increased likelihood of infection. They found that perceptions of susceptibility might not be related to actual risk levels as measured by STI tests. Furthermore, Muller et al. (1992) in a comparison of HIV-positive and HIV-negative individuals found that previous risk, measured in terms of reported lifetime numbers of previous partners and reported number of casual sexual contacts in the previous 6 months, did not appear to substantially differentiate HIV positive from HIV-negative individuals. This is an interesting finding, in so far as it suggests that the behavioural measures of risk commonly used by researchers may not be highly predictive of infection. 


\section{Additional Factors in the Demand for VCT}

Apart from a perception of risk, another salient factor that appears to influence the individual's decision to be tested is the perceived benefits of testing. A number of studies have focused on this question by looking at who comes for VCT and, more importantly, why they do so (Muller et al, 1993, Gibney, Wade, Madzime \& Mbizvo, 1999, Balmer, Grinstead, Kihuho, Gregorich, Sweat, Kamenga, Plummer, O'Reilly, Kalibala, Van Praag \& Coates, 2000, Maman et al, 2001). An ability to plan for the future is perhaps the main perceived benefit of testing, either because it allows couples to proceed with unprotected sexual intercourse, marriage and pregnancy or because it allows individuals to prolong and modify their lives in the face of HIV infection (Gibney et al, 1999, Maman et al, 2001).

Other researchers have focussed their attention on profiling the socio-demographic characteristics of who comes for VCT in an attempt to identify variables associated with the demand for VCT (e.g. education, age, gender, marital status, etc.). These studies have, by and large, provided a number of inconsistent findings (Brimmer, Gillespie \& Schomer, 1996, Ayiga et al, 1999, Marum, Barnaba, Rayfield, Campbell, Dillon, Fridlund \& Msowoya, 2000) with the result that while these studies do provide a demographic profile of VCT clients in a specific area at a specific time, they tell us nothing about the nature of the decision-making process involved in being tested for HIV.

Beardsell and Coyle (1996) therefore argue that most quantitative studies regarding VCT users have merely succeeded in identifying a variety of socio-demographic factors that are statistically associated with their dependent variables, but have not shed real light on the question of who uses VCT and why. One study did attempt to address this question (who comes for VCT?) from another perspective, i.e. that of the research participants themselves (Kipp et al, 2001). Respondents were asked to identify their own reasons for returning or not returning for a result. However, the full decision-making process was not explored and participants were generally simply asked to provide a reason for non-attendance. In fact, reasons offered by participants would have been better labelled 'excuses' than 'reasons'. Such responses included being sick, visited relatives, or forgetting (Kipp et al, 2001). This is because most of the said reasons could be avoided, given that the service is free and always open. 
Maman et al. (2001) point out that gender inequality is a significant factor affecting the uptake of VCT in women. Fear of a partner's reaction and partner's negative attitudes towards testing will act to limit the number of women who choose to be tested. Thus, it would appear that unequal power relations that limit women's control over their risk of infection in the first place also limit testing behavior. There also appear to be important differences in the factors that motivate men and women to ask for a test. For example, it would appear that while men tended to be tested to confirm that they are negative, women are more likely to have a perception of personal susceptibility and therefore will engage in testing to find out if they are positive (Maman et al, 2001).

In summary, studies on factors influencing Voluntary counselling and Testing uptake concentrate on three areas which include perceived vulnerability to HIV infection, perceived benefits of testing, and gender relations. Further, the question as to whether VCT is effective in achieving primary and secondary infection to HIV is doubtful due to methodological limitations in the studies reviewed such as lack of randomization, use of inappropriate indicators to measure behavior change, and lack of a standardized VCT process. This raises concern as to whether exploring issues of efficacy is the right question for VCT research in African settings. Following this, rather than continuing with the debate as to whether VCT attendance influences behavior change among the service users or not, this research sought to explore conditions under which VCT is effective on African setting. Specifically, the research limited itself to determining the dynamics involved in the service delivery in an attempt to establish the conditions under which optimum results can be achieved. 


\section{Chapter Three \\ Research Methodology}

\subsection{Introduction}

This chapter presents the methodology used in conducting the research. It starts with a discussion of the theoretical framework used in the study after which research area, Target Population and data collection methods are discussed. The chapter ends with information of the data management.

\subsection{Theoretical framework}

The researcher took an objectivist approaches by assuming that factors that influence VCT uptake can be known by administering to the respondents, a standardized tool to measure various aspects relevant to the research such as respondents' knowledge on HIV/AIDS, HIV/AIDS risk perception and respondents' attitude towards the VCT service and other factors that may be associated with individual's decision to utilize the VCT service. However it is also assumed that such measurement provide limited information on decision making and hence a need of other approaches that will complement the objective approach have been used. Consequently a mixed research method methodology employing quantitative and qualitative data collection methods was deemed as the most appropriate.

The research was guided by post-positivist theoretical perspective. Post-positivists believe that human knowledge is not based on unchallenged, solidified foundations; but it is hypothetical. Nevertheless, they believe there are real grounds for asserting these beliefs, although these warrants can be modified or withdrawn in the light of further investigation (Crotty 1998).

Post-positivism assumes a critical-realist ontology and an empiricist epistemology (Denzin \& Lincoln 2003). Like its earlier Positivist cousin, it posits a reality that is "out there" to be discovered, however, in contrast, the reality can only be known imperfectly and within probability, not certainty as in the naïve-realist position of Positivism. Post-positivism postulates, like Positivism, that the universe is comprised of objective, constant objects and structures that exist as observable entities, on their own, independent of the observer's appreciation of them (Denzin \& Lincoln 2003). Factors such as attitudes towards the VCT service, knowledge about HIV/AIDS, risk perception, among other things has been associated with service utilization (Forsythe et al, 2002). These can be measured to some degree using a standardized research tool and the level to which this influences VCT uptake be known. However contradictions which may arise from the quantitative data may be 
clarified by collecting qualitative data. In addition qualitative data provide opportunity for greater weight into decision making process

\subsection{Study Area}

This study was conducted in Nakuru central district one of the seventeen districts in the Rift Valley province of Kenya. Rift valley is one of Kenya's seven administrative provinces outside Nairobi, the largest and one of the most economically vibrant provinces in Kenya. The province covers an area of $173,854 \mathrm{~km}^{2}$ with a population of $1,187,039$ inhabitants making it the largest and most populated in the country. This province was selected for the study because it has one of the highest numbers of people living with HIV/AIDS. According to the NASCOP (2008), Rift Valley and Nyanza together contributed $50 \%$ of the People living with HIV/AIDS virus in Kenya.

\subsection{Target Population.}

The target population were people aged above 18 years living in Nakuru district. This age bracket was selected due to the fact that it is the age which is highly sexually active; and so the age when people are at highest risk. Also according to NASCOP (2008), people in this age carry the biggest burden of the disease compared to other age categories. The district was selected for its large population and the fact that it is the provincial headquarter to Rift Valley province.

\subsection{Eligibility criteria}

\section{Inclusion criteria}

To be eligible for inclusion to the survey questionnaire and to participate in focus group discussion respondents needed to fulfill the following criteria.

1 Be aged between 18 and 60

2 Be a resident in the district for at least six months prior to the commencement of the study. 


\section{Exclusion criteria}

A respondent meeting the above criteria were only excluded from the study on the basis of the following:

1 Where they were too sick to respond to the questionnaire or participate in a focus groups discussion.

2 Where they were under the influence of drugs or alcohol. This is because the opinions they express while under influence may not be reliable nor could it be valid.

3 Where they were mentally incapacitated. This is because under Kenyan law they do not have the capacity to give consent and also their opinions may not be reliable nor valid

\subsection{Data collection Methods}

\section{Quantitative data collection}

A structured questionnaire was used as the quantitative method of data collection. The questionnaire included items on HIV/AIDS knowledge, attitude and practice and social demographic information on the respondents. The questionnaire included adopted items from Carey et al, (1997) (questions 920) and UNAIDS (1999) (questions 40-45). The rest of the items were constructed by the researcher. The use of survey assisted the researcher to accurately describe the community through reaching as many of members of the target community as possible.

The benefits of the use of a structured questionnaire are many, First, it enabled the researcher to quantify community members with various community characteristics in relation to the utilization of VCT services, allow statistical analyses to establish associations between respondents characteristics and VCT utilization; make estimations on aspects such as the number of people who are aware of the VCT existence and the number of people who are aware of benefits of its utilization among other things.

Another advantage of using a structured questionnaire is that it was found to be an economical research tool in that due to the focus provided by standardized questions, only questions of interest to the researcher were asked, recorded, codified, and analyzed. Time and money was not spent on unnecessary questions (Baker, 1994). Moreover, structured questionnaires were found to be an efficient way of collecting information from a large number of respondents, provided a way in which 
statistical techniques can be used to determine validity, reliability, and statistical significance of responses (Rosenberg et al, 1993). This technique is also flexible in the sense that a wide range of information can be collected from the same individual without them feeling overworked.

\section{Sampling design}

The target population to which the structured questionnaire was administered were respondents aged between 18-60 years using VCT facilities in Nakuru central district. Study participants were drawn using the district health facility list maintained by the Provincial Health Officer. This sampling frame covers all facilities in all districts of the province

A three-stage sampling procedure was used. Firstly, all the facilities were stratified on the basis of them being urban or rural $(\mathrm{H}=2)$. The second stage involved selecting facilities in which to administer the questionnaires. The number of urban and rural facilities from which the questionnaire was administered was allocated proportionately to the population in rural and urban residence. The sample for each stratum was then shared equally among the strata facilities selected. Finally, all clients coming for VCT service in those facilities were requested to respond to a structured questionnaire until the required sample in the facility was attained. For each facility in which

questionnaires were administered, one key informant interview (with a counsellor / VCT manager) was also conducted. .

\section{Sample Size Determination}

A 95\% confidence level with $\pm 5 \%$ margin of error (MOE) was desired for this study. The unadjusted sample size $\left(n^{\prime}\right)$ required for $\pm 5 \%$ MOE using the conservative proportion $(\mathrm{p})$ of $\mathrm{p}=0.5$ (or 50\%) is: $n^{\prime}=\left(\frac{Z}{M O E}\right)^{2} p(q)$

Where

- $\mathrm{n}$ is the desired sample size

- $\mathrm{Z}^{2}$ is the standard normal deviation at the required confidence interval.

- $\mathrm{P}$ is the estimated proportion of people in the target population who would like to be tested for HIV at VCT centers but due to many factors have not taken the test. (for P in this case , a conservative proportion of $50 \%$ was taken) 
- $\mathrm{q}=1-\mathrm{p}$

Therefore, sample size for the respondents was:

$$
\mathrm{n}=\frac{1.96^{2}(0.5 \times 0.5)}{(0.05)^{2}}=384
$$

The population from which this sample was being drawn is big enough (above 10,000) and hence finite population correction (FPC) was ignored because N (total number of clients) was large, and unadjusted sample size was larger than FPC adjusted sample size, making $n^{\prime}$ the more conservative figure.

A Kenyan study investigating behaviour change after visiting VCT conducted by Arthur et al (2007) reported a response rate of 78\%, while another one conducted in Ethiopia, Kenya's next door neighbor, by Getachew in 2004 (Getachew, 2004) on factors influencing VCT uptake showed a response rate of $97 \%$. It was therefore estimated that response rate $(\phi)$ of $80 \%$ will be achieved in the current study. Consequently, the new sample size $\left(n_{\text {adjusted }}^{\prime}\right)$ with $\phi=80 \%$ is $n_{\text {adjusted }}^{\prime}=\frac{n^{\prime}}{\phi}=480$ clients.

\section{Sample allocation}

Sample size of 480 was equally distributed between the two strata using proportional allocation: $n h$ $=\frac{N h}{N} \times \mathrm{n}$. Refer to Table 1 for figures. Proportional allocation was used to ensure same sample weight for all strata.

Table 1: Estimations for stratified sample design

\begin{tabular}{|l|l|l|l|l|}
\hline Stratum & $h$ & $\begin{array}{l}\text { Population } \\
\text { served: } N h\end{array}$ & $\begin{array}{l}\text { Approximate } \\
\text { number of facilities } \\
\text { need to be selected }\end{array}$ & $\begin{array}{l}\text { Sample size } \\
\text { per stratum } \\
: n h\end{array}$ \\
\hline $\begin{array}{l}\text { Urban } \\
\text { facility }\end{array}$ & 1 & 353,007 & 8 & 160 \\
\hline $\begin{array}{l}\text { Rural } \\
\text { facilities }\end{array}$ & 2 & 834,032 & 16 & 320 \\
\hline Total & - & $1,187,039$ & 24 & 480 \\
\hline
\end{tabular}




\section{Qualitative data collection}

There were many benefits of including qualitative data collection methods in the study; first, the approach provided more contextual details than is possible with use of survey methods alone. A decision to utilize a voluntary counselling and testing service may be influenced by personal experience or societal factors. Consequently, in order to answer the questions of what factors influence individual decisions to utilize a VCT service, this study must take in to consideration the individual and the social context.

Secondly, community utilizing VCT services is at the heart of this inquiry. For the VCT service to be of benefit to the community, it must be modeled to fit the community. Community context here was deemed to be particularly important in that Kenyan communities tend to differ significantly in many ways. For example, Kenyan rural communities normally spend most of their time in the farms and may not be available in specific times when the VCT centre is opened. On the other hand urban communities may have more time at their disposal and hence more time to access VCT service. Other contexts such as culture, education level, income and so forth within the targeted community were taken into consideration while designing a project. Further, VCT relates to HIV/AIDS which relates to sexuality. Sexuality is not a series of individual, episodic behaviors linked to specific acts and the physical body, but represents a range of sexual activities and norms, whose meaning and significance for both the individual and society change over time (di Mauro, 1995, pp. 4-5), hence a need for an inquiry that will cover these grounds.

Another advantage of including qualitative inquiry is that it can offer understanding of the meanings behind the actions and terminologies that may be used by individual or the community. Meaning depends upon context, and the interpretation of action or opinion must take account of the setting in which it is produced (Dey, 1993).

Finally the inclusion of qualitative aspects in the current proposed study may help in correcting the bias that may occur during the survey method. Heisenberg claims that, 'what we observe is not nature itself, but nature exposed to our method of questioning' (Heisenberg, 1958). The data, which are gathered from that research, might be, in part, a product of the research process. The time and context in which the data were gathered will also influence those data (Dervin, 1997). Therefore, 
using qualitative research may provide some balance to the bias that may result from the survey method.

\section{Key informants}

According to Creswell (1998), key informants are individuals who are targeted for data collection because their information provides an accurate and relatively broad perspective on the setting as well as lead to other sources of information. In this study, five Key informants were recruited and included VCT Counsellors/managers. These were recruited purposively from the facilities in which the survey questionnaire was administered. They were however, expected to have worked in the centre for at least a six month period preceding the study. The purpose of conducting these interviews was to shed some light into such factors as their training needs, operational hours, and work load, other services they offer at the centre, service quality and issues relating to the supply of test kits and reagents, since these may influence the service uptake. In total, five key informant interviews were carried out.

The justification for conducting these interviews is that the researcher intended to get an in-depth account of issues associated with the running of the VCT centers including policy issues. Professionals working at the centre were thought to be more likely to have a better understanding of issues to do with VCT policies and those issues relating to the clients they serve. The advantage of using key informant interviews is that they were easy to administer and their ability to generate information from people directly involved with the service delivery.

\section{Focus Group Discussions}

The participants in the focus group discussions were recruited through Faulu Kenya, an NGO that is involved in developmental issues in the district. Men and women who have not used VCT service were requested to participate. Recruitment of participants considered age and sex characteristics to achieve homogeneous groups in terms of age and sex, to encourage free participation during the discussions. Six focus group discussions were carried out. The focus group discussions centered on participants perceptions of HIV/AIDS and VCT. 


\section{Reliability and Validity of the Study Qualitative Data}

Validity in research refers to the degree to which the data corresponds to the 'way it is' within the phenomenon which is being investigated. To ensure credibility of the data collected in this study, triangulation was done. Triangulation refers to collecting data from different sources to confirm the validity. Another way that enhanced validity was including independent checks on the data with multiple persons involved in the service. Additional focus group discussions were also conducted to ensure the validity of the data and more specifically on issues found to be inconsistent during the preliminary data analysis.

On the other hand, reliability is the consistency of measurement, or the degree to which an instrument measures the same way each time it is used under the same condition with the same subjects. To ensure the reliability of qualitative data, the researcher trained the assistants by going through the focus group and key Informant schedules with them to ensure that items in both focus group discussions and key informant guides means the same to all research assistants. Bi-lingual Kiswahili and English research assistants were used to conduct Focus group discussions and the items in the guide were translated into the two languages prior to the research.

\section{Structured Questionnaire Data}

Convergent validity of the data collected using a structured questionnaire was ensured by checking it against other sources such as literature and qualitative data and clarifying any inconsistencies.

On the other hand, to ensure reliability of the data collected using the structured questionnaire, the following was done. A pilot study was conducted and problematic items adjusted accordingly. Finally the researcher trained all research assistants to ensure that they understood each item in the questionnaire.

\section{Qualitative Data Analysis}

The analysis was inductive which implies that categories of analysis were not imposed a priori on the data but were identified through the analysis process using the following steps (Pope \& Mays, 2000).

\section{Step 1 Transcribing}

The recorded data was transcribed. All the focus groups discussion were in Swahili and therefore the initial transcription was in Swahili but later it was translated into English language. 


\section{Step 2: Preliminary Exploratory Analysis.}

During Step 2 of data analysis the researcher explored the data in order to become familiar with the interview information. This entailed reading the transcript multiple times. From this initial review of the transcript it was hoped that the researcher would begin to identify themes emerging from the data. Sections of the transcripts that reflected a theme were identified and notations made to record ideas that the researcher identified while reading the data.

\section{Step 3: Making Connections to the Research Questions.}

Step 3 involved describing and further developing the themes from the data to answer the research questions. The themes identified in Step 2 were revisited with the research questions as the lens for analysis. A coding scheme that best defined the themes identified was developed to provide a way to break up the data for further analysis. At this point the transcript was re-read with these codes in mind and sections of the data bracketed and coded. A color code was used to identify these blocks.

\section{Step 4: Inter-rater reliability.}

To ensure reliability of the coding scheme, the researcher requested another person to assist. To do this the person was requested to review the transcript and use the coding scheme used in step three above to code the data. Results were then compared and any discrepancies discussed and resolved.

\section{Step 5: Interpreting Findings.}

Once all of interview data was coded it was then divided into themes. This was done by cutting up the interview data "blocks" and sorting them into each of the codes identified above. Pasting the data onto index cards assisted the sorting process. The original in its entirety was preserved.

Finally the data was reviewed within the themes or categories, and an understanding of each theme reached. Quotes were selected that best illustrated the meaning of the category .

This process was not without problems. Firstly, most of the recording was in Swahili language. This required me to do a translation as is a requirement for this thesis to be in English. While care was done to ensure that the original themes were maintained there are possibilities that it was not fully 
achieved as some Swahili words do not have equivalent in English. Secondly the fact that I am the one who did the translation and I was not involved in conducting some of the interviews, having enlisted help of a research assistants, meant that I could not draw on additional implicit information (body language, tone of voice etc) that may help me choose the appropriate translation. Moreover, while I am able to speak in Swahili fluently I am not a native speaker and therefore I could have missed some concepts.

\section{Ethical statement}

The fact that key informants included in the study are few in number makes it impossible to maintain their anonymity in regard to the data they give. Confidentiality is ensured instead.

Another ethical limitation encountered in this study includes the fact that some of the respondents were not be able to comprehend some issues in the questionnaire properly and therefore needed to be guided through the questionnaire. This made it impossible for the information they gave to be anonymous to the research assistant concerned. This was however addressed by training research assistants on the need to maintain confidentiality during and after the process.

\section{Other ethical Considerations.}

The approval to conduct this study was obtained from the Human Ethics Committee of Victoria University of Wellington New Zealand and the Moi Teaching and Referral Hospital Eldoret Kenya. 


\section{Chapter Four}

\subsection{Introduction}

\section{Quantitative Data Findings}

This chapter presents the quantitative findings. The chapter starts with presenting social demographic data findings, after which the findings on HIV/AIDS knowledge is presented. The chapter ends with findings on risk perception among the respondents responding to structured questionnaire.

\subsection{Social demographic data findings}

A structured client-exit questionnaire was administered with the help of three research assistants to 480 respondents drawn from $16 \mathrm{VCT}$ centers of the district; out of which 422 were completed and returned hence a response rate of $87.9 \%$. Of these 268 (63.5\%) were male and $154(36.5 \%)$ were female. The mean age of the respondents was 26.58 with a standard deviation of \pm 7.76 . The youngest respondent was aged 16 years while the oldest respondent was 60 years. Other social demographic characteristics of the respondents were as shown in Table 2 below.

Table 2 Social Demographic Characteristics of the Respondents.

\begin{tabular}{|c|c|c|}
\hline Characteristic & Frequency & $\%$ \\
\hline \multicolumn{3}{|c|}{ Marital status } \\
\hline Currently Married & 142 & 33.6 \\
\hline Living with a man/woman as if we are married & 94 & 22.3 \\
\hline single/Never Married & 99 & 23.5 \\
\hline Divorced & 11 & 2.6 \\
\hline Widow/widower & 76 & 18 \\
\hline Total & 422 & 100 \\
\hline \multicolumn{3}{|c|}{ Religion of the respondents } \\
\hline Catholic & 30 & 7.11 \\
\hline Protestants & 352 & 83.4 \\
\hline Muslim & 38 & 9.0 \\
\hline African tradition & 1 & .2 \\
\hline Total & 422 & 100 \\
\hline \multicolumn{3}{|c|}{ Education of the respondents } \\
\hline Have never attended school & 15 & 3.6 \\
\hline Did not complete primary school & 68 & 16.1 \\
\hline Primary & 172 & 40.8 \\
\hline secondary school & 105 & 24.9 \\
\hline $\begin{array}{l}\text { Post secondary school (including college, } \\
\text { university, other }\end{array}$ & 62 & 14.7 \\
\hline Total & 422 & 100 \\
\hline \multicolumn{3}{|c|}{ Occupation of the respondents } \\
\hline Student & 70 & 16.6 \\
\hline Farmer & 136 & 32.2 \\
\hline Business & 147 & 34.8 \\
\hline Professional & 69 & 16.4 \\
\hline Total & 422 & 100 \\
\hline
\end{tabular}




\subsection{Level of knowledge on HIV/AIDS}

The level of HIV/AIDS knowledge among the respondents was evaluated by asking a set of ten questions as a part of the semi structured interview. The knowledge items were in six domains that included awareness of the disease, the disease cause, and mode of transmission, disease treatment, risky behaviors, and preventive measures. The majority of the respondents 405 (96.2\%) indicated they had heard of the disease, 396 (93.2\%) correctly identified HIV virus as the cause of the disease with $392(92 \%$.) correctly asserting that there is no cure for HIV/AIDS.

Regarding the sources of information on HIV/AIDS and VCT, respondents had multiple responses. More than half (52.6\%) reported to have heard about it from the mass media (Radio and Television) while others got the information from other sources like relatives and friends, religious leaders peer educators and health workers as shown in Figure 1.

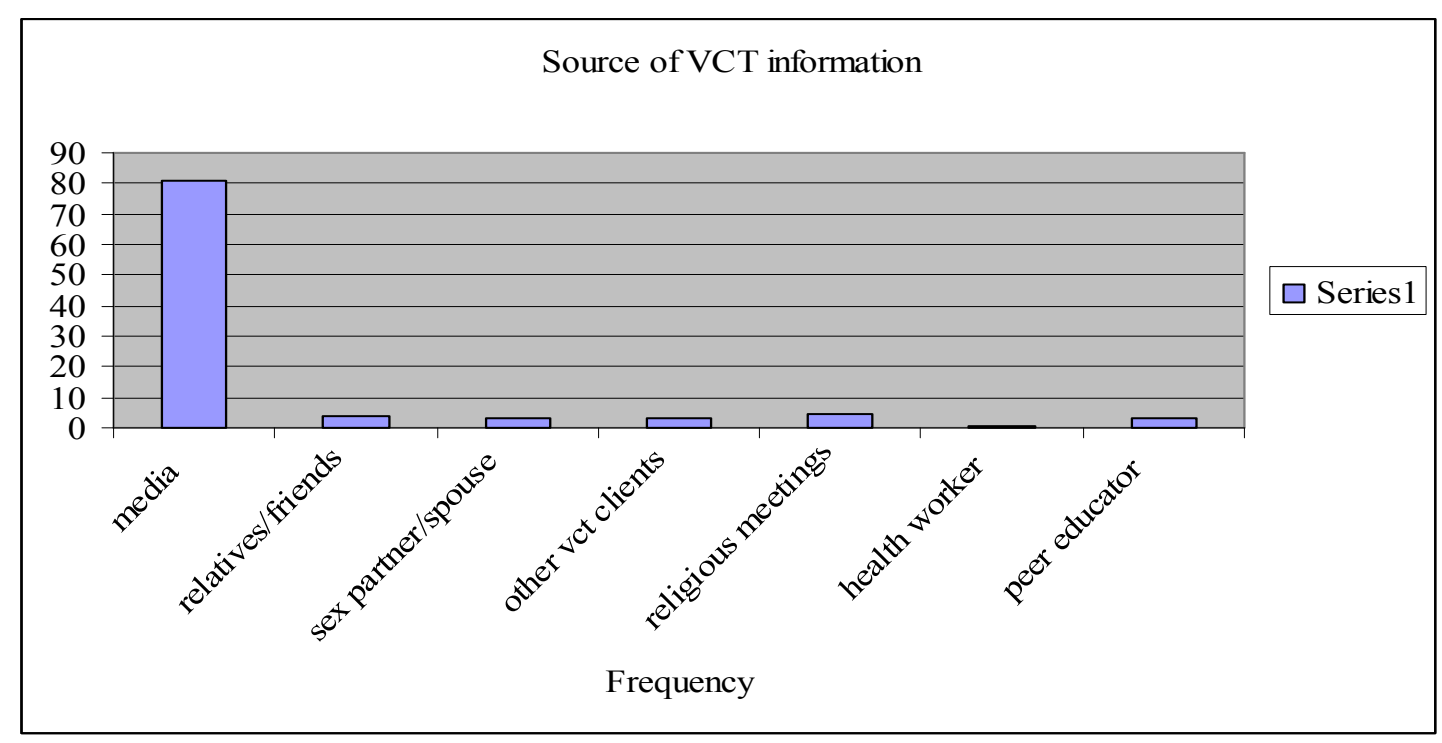

Figure 1. Sources of HIV/AIDS information for the respondents 
Regarding the level of knowledge on HIV/AIDS prevention, a majority of the respondents depicted a high level of knowledge. Table 3 below shows respondents responses to a set of questions on issues related to with $\mathrm{HIV} /$ prevention.

Table 3. Respondent's responses on issues to do with HIV/AIDS prevention

\begin{tabular}{|l|l|l|l|l|l|l|}
\hline Item & \multicolumn{2}{l|}{ True } & \multicolumn{2}{l|}{ False } & \multicolumn{2}{l|}{ Don't know } \\
\hline & $\mathrm{f}$ & $\%$ & $\mathrm{f}$ & $\%$ & $\mathrm{f}$ & $\%$ \\
\hline $\begin{array}{l}\text { Abstaining from sex can prevent one } \\
\text { from contracting HIV. }\end{array}$ & 404 & 95.7 & 18 & 4.3 & 0 & 0 \\
\hline $\begin{array}{l}\text { Use of condom can reduce ones } \\
\text { chance of contracting }\end{array}$ & 357 & 84.6 & 59 & 14 & 6 & 1.4 \\
\hline $\begin{array}{l}\text { *Limiting sex to one partner can } \\
\text { reduce once chance of contracting } \\
\text { HIV }\end{array}$ & 409 & 96.9 & 3 & 3.1 & 0 & 0 \\
\hline $\begin{array}{l}\text { Avoiding sex with prostitutes can } \\
\text { reduce one's chance of contracting } \\
\text { HIV }\end{array}$ & 413 & 97.2 & 9 & 2.1 & 0 & 0 \\
\hline $\begin{array}{l}\text { Avoiding sex with a person who has } \\
\text { many partners can reduce one's } \\
\text { chance of contracting HIV }\end{array}$ & 406 & 95.5 & 16 & 3.8 & 0 & 0 \\
\hline $\begin{array}{l}\text { Avoiding sex with homosexuals can } \\
\text { reduce one's chance of contracting } \\
\text { HIV }\end{array}$ & 393 & 92.5 & 29 & 6.8 & 0 & 0 \\
\hline $\begin{array}{l}\text { Seeking protection from a traditional } \\
\text { healer can reduce one's chance of } \\
\text { contraction HIV }\end{array}$ & 16 & 3.8 & 402 & 95.3 & 0 & 0 \\
\hline $\begin{array}{l}* \text { Somebody Can get the AIDS virus } \\
\text { from mosquito bites }\end{array}$ & 13 & 3.1 & 406 & 96.9 & 0 & 0 \\
\hline
\end{tabular}

*Some of the respondent did not respond to the marked Items hence total response were less than 422 
In general, findings in this section indicate a high level of HIV/AIDS knowledge among the respondents. This could be due to the fact that there has been a lot of HIV related work in this community and also the fact that this was a client exit interview meaning that some of the knowledge could have been attained during the counselling process. A bivariate analysis using Pearson chi square test on knowledge as the outcome of interest against social demographic characteristics of the respondents including age, sex, education level of the respondents and occupation showed no significant results on all four characteristics.

\subsection{Risk perception}

HIV risk perception is an important determinant of behavior change and therefore complementing HIV and other sexually transmitted infections (STIs) prevention measures. Regarding this, respondents were asked if they considered themselves to be at risk of HIV infection. A majority of $299(70.9 \%)$ respondents felt that they were at risk while 123 (29.1\%) felt they were not. Those who felt to be at risk of infection were further asked to rate their level of perceived risk on a scale of high, moderate or low. Slightly more than a half, $153(51.2 \%)$ felt that they were at high risk of contracting HIV, 75 (25.1\%) considered themselves to be at moderate risk while the rest 71(23.7\%) perceived their risk of infection to be low. Using Chi square test, marital status of the respondent was found to be significant in determining whether the respondent felt at risk or not. $\left(\chi^{2}=9.929, \mathrm{P}=\right.$ 0.054). Single, divorced, widow/widower respondents were 1.35 less likely to feel at risk compared to those who were married/living with a man or woman as if married.

To assess their risk of exposure to the HIV virus, respondents were asked to state if they had used a condom in their last sexual encounter. 413 (97.9\%) respondents responded to this question out of which $258(61.1 \%)$ reported having not used a condom in their last sexual encounter. There was no statistical significant difference on the use of condom between the two genders.

Further, in an open ended question, respondents were asked to state some of the benefits they expected to accrue in attending VCT. Responses to this included knowing their HIV sero-status, getting drugs if infected, getting good counselling, enjoying confidentiality, and acquiring HIV knowledge. Other benefits of VCT mentioned included enhancing risk reduction and being able to plan for their future. 
To measure HIV related stigma, respondents were asked two questions touching on discrimination and their willingness to care of somebody who is infected. A majority of the respondents, $92.9 \%$, were willing to take care of a HIV positive patient. The question on discrimination was asked in the form of a likert scale. Table 4 below shows how the respondents responded to this by sex.

Table 4. Respondents level of agreement to assertion that people who test positive are most likely to be discriminated against by gender.

\begin{tabular}{|c|c|c|c|}
\hline & \multicolumn{3}{|c|}{ Sex of the respondent } \\
\hline & Male & Female & Total \\
\hline \multirow[t]{2}{*}{ strongly disagree } & 73 & 78 & 151 \\
\hline & $48.3 \%$ & $51.7 \%$ & $100.0 \%$ \\
\hline \multirow[t]{2}{*}{ disagree } & 31 & 10 & 41 \\
\hline & $75.6 \%$ & $24.4 \%$ & $100.0 \%$ \\
\hline \multirow[t]{2}{*}{ agree } & 54 & 47 & 101 \\
\hline & $53.5 \%$ & $46.5 \%$ & $100.0 \%$ \\
\hline \multirow[t]{2}{*}{ strongly agree } & 29 & 13 & 42 \\
\hline & $69.0 \%$ & $31.0 \%$ & $100.0 \%$ \\
\hline \multirow[t]{2}{*}{ don't know } & 81 & 6 & 87 \\
\hline & $93.1 \%$ & $6.9 \%$ & $100.0 \%$ \\
\hline Total & 268 & 154 & 422 \\
\hline
\end{tabular}

On running Chi square test, sex of the respondent was found to be statistically significant in determining the position a respondent took in regard to the statement that "a HIV positive person is likely to be discriminated against" $(\chi 2=55.4, \mathrm{P}=0.001)$. More female respondents than male were likely to hold opinion that HIV positive people are likely to be discriminated against.

\subsection{VCT access and quality}

Regarding VCT service accessibility, respondents were asked to state whether they had previously attempted unsuccessfully to access the service. A majority of 339 (80.3\%) had tried unsuccessfully to access the service at least once with $38(9 \%)$ having tried twice, $9(2.1 \%)$ thrice and $10(2.4 \%)$ respondents having tried more than four times. On running Chi square test, sex and age of the respondent were found to be significant in determining whether a person had unsuccessfully tried to 
access a VCT service or not, with $(\chi 2=9.375, \mathrm{P}=0.05)$ and $(\chi 2=29.38, \mathrm{P}=0.003)$ for sex and age respectively. Table 5 below shows the distribution of the respondents who had unsuccessfully tried to access VCT service by sex and age.

Table 5. Distribution of the respondents who had unsuccessfully tried to access VCT service by number of times sex and age

\begin{tabular}{|l|l|r|r|r|r|r|}
\hline \multirow{4}{*}{} & \multicolumn{6}{|c|}{ Number of times the client has tried accessing VCT service } \\
\cline { 2 - 8 } & & once & Twice & Thrice & $\begin{array}{r}\text { Four and } \\
\text { above }\end{array}$ & Total \\
\hline $\begin{array}{l}\text { Sex of the } \\
\text { respondent }\end{array}$ & Male & 174 & 26 & 9 & 9 & 268 \\
\cline { 2 - 8 } & Female & 108 & 12 & 0 & 1 & 154 \\
\hline \multirow{2}{*}{$\begin{array}{l}\text { Age } \\
\text { category } \\
\text { of the } \\
\text { respondent }\end{array}$} & Total & $\mathbf{2 8 2}$ & $\mathbf{3 8}$ & $\mathbf{9}$ & $\mathbf{1 0}$ & $\mathbf{3 3 9}$ \\
\cline { 2 - 8 } & $16-25$ & 149 & 13 & 1 & 8 & 215 \\
\cline { 2 - 7 } & Over 45 & 109 & 20 & 8 & 2 & 173 \\
\hline & Total & 16 & 0 & 0 & 0 & 15 \\
\hline
\end{tabular}

*339 out 422 respondents responded to the question as to whether they had previously tried to access VCT service unsuccessfully

Females were 1.7 times less likely than males to have tried unsuccessfully to access VCT service. On the other hand younger people (16-35 years) were more likely to have unsuccessfully tried to access the service compared to people aged above 36 years. This may suggest that the service being offered may not be youth and male friendly.

On the location of the VCT centre from the respondents' home, respondents were asked to state whether the centre they took their HIV test from was the nearest to their home. $303(71.8 \%)$ responded to the affirmative while, the rest 119 (28\%) asserted that the VCT centre where they took their test from was not the nearest to their homes. Those who indicated as having travelled far to take the test were further asked to state their reasons as to why they had opted to take the test from their specific centre of testing. Some of the reason given included being more conveniently located as compared to other VCT centre near respondent's home $11(9.2 \%)$, preference to be tested away from home where they are not known $17(14.2 \%)$, being able to secure a HIV test appointment 
immediately 65(54.6\%), and being referred to a particular VCT centre by a health worker 26 $(21.8 \%)$. It is worthy to note that being able to secure HIV test appointment immediately was reported by the largest proportion of those who had travelled for a longer distance for the test.

To gauge the quality of the service offered at the VCT various questions relating to the client satisfaction with the service, service accessibility to the client, convenience of the counselling room, privacy enjoyment and the time spent with the counsellor and the Counsellor's attitude towards the client were asked.

Regarding the level of respondent's satisfaction with the service they received, respondents were asked to rate the service in terms of whether it was satisfactory, good or bad. $61 \%$ reported the service to be satisfactory, $33.4 \%$ reported the services to be good while only $5 \%$ thought that the services were bad.

On the convenience on the counselling room, $409(96.9 \%)$ of the respondents reported that it was convenient while 13 (3.1\%) reported that the counselling rooms were not convenient. On running Chi square test, age of the respondent was found to be significant in determining whether a client found couselling room convenient or not $(\chi 2=26.2, \mathrm{P}=0.001)$. More young people 16-35 reported the counselling room to be inconvenient compared to people above 26 years.

Regarding privacy during counselling, 398 (94.3\%) reported that they enjoyed privacy while 24 (5.6\%) did not. Since privacy is crucial in VCT counselling, it should be noted that the smaller percentage could have had important issues with privacy. This needs to be addressed at the counselling centres.

Regarding time spent with the counsellor, nearly $275(65.2 \%)$ reported that the time spent was just right. $93(22 \%)$ reported that the time was too long while 54(12.8\%) reported that the time was too short. There was no statistically difference in terms of age and sex in regard to observation on time spent with the respondents.

Since professional counselling has stipulated time for each session, the clients who thought the time was too short may have had too many issues that had to be addressed while those who reported that the time was too long could have gone just for testing. They may not have wanted to address the 
issues the Counsellors thought were important. This emphasizes the importance of the Counsellors to address the issues directly as they are raised by the clients.

On the counsellors attitude towards the client 258 (61.1\%) of the respondents said it was satisfactory, $140(33.2 \%)$ said it was good and 24(5.7\%) classifying it as bad. There were no statistically significant differences in terms of gender and age on the level of satisfaction of the counsellor's attitude by the respondents. 


\section{Chapter five}

\section{Qualitative data findings}

\subsection{Introduction}

This chapter presents the qualitative data findings. The chapter begins with the focus group discussions findings. Specifically findings on attitudes, perception and social stigma regarding HIV/AIDS are presented after which findings on VCT service perception, attitudes, awareness; and motivations and barriers to its utilization are presented. The chapter ends with presenting the key informants findings.

\subsection{Attitudes, perceptions and social stigma regarding HIV/AIDS}

Most of the people who participated in the focus group discussions were familiar with the matter relating to HIV/AIDS, and admitted to having had a discussion on the topic. Some of the people with whom they had discussed the disease included close friends, family members, older men and religious leaders. Among the young people who admitted to ever discussing the disease, close friends and family members were most preferred with the main goal of the discussion being how to protect themselves from the disease. This was particularly commonly expressed by young males. For example one male remarked

Yes I do discuss this with my friend, it is far much easier to do this with them, $i$ want to know how to protect myself- male youth

In regard to those who never discuss the disease, varied reasons were given. These included lack of information about the ailment, shame, and the fact that some did not feel comfortable discussing sexual matters in the open. Female participants were more likely to register shame and discomfort in discussing the matter in the public compared to their male counterparts. One of the young female participants remarked

\section{'I think it is shameful to discuss something like that in the public'- Female youth}

A question as to whether they would like to know their HIV status elicited mixed reaction. Those who would want to be tested cited such benefits as the ability to plan for their future, increasing their 
health status awareness and hence able to protect themselves and their partners in future. The following remark by a young male participant is a typical of expressions made by the participants.

Of course I would want to be tested...I want to know how my body is and also know how my partner is before we get married. - Young male

For those who did not want to know their HIV status, varied reasons were given. These included fear of the fact that if found positive they would be discriminated against in the community, overpowering fear of mental and physical distress and certain early death if one is HIV positive; which clearly outweighed the somewhat intangible benefits of being able to plan one's life and not infect others. This was captured in such expressions as the following.

I have been thinking about it, I am not yet confident to take the test because I do not know how I would be able to handle the results. I am not sure how I will be able to face people if I am found positive. - Male youth

Participants in married unions feared the possibility of dying early and leaving behind their children without a person to take care of them. One adult participant stated the following.

I have children, if I am found that I am infected I would be miserable. I don't want to start getting stressed about who will take care of my children when I am gone. - Female adult

Across all the categories of participants there was a common feeling that people who test positive to HIV may not discuss their status for fear of being abandoned and loss of reputation. Where they choose to do so, it was reported that they do that with other people who have tested positive to HIV or family members. The general feeling was that they confided with people who are also infected and family members so that they can get support. However, while family members were mentioned as possible people with whom a HIV positive person may confide, it was remarkable in the findings that women were not likely to discuss the results with their spouses unless they went for the test together. The following is a remark by one married female adult. 
There is no way I can tell him, I do not want problems, and he will ask me why I went to the centre without his knowledge. I know he would be angry with me. - Married female adult.

Most of the participants were of the opinion that many people of their age or sex were worried about contracting HIV AIDS. Some of the main reasons given as to why people are worried included the view that if infected with HIV you die slowly as compared to other diseases and also the view that contracting HIV gave certainty of an early death. A married female stated the following.

Yes I am worried, if you get the disease, people will watch you as you die slowly and they will not be able to help you. People will also run away from you, you will lose your dignity... others will think you are promiscuous- married female adult.

Youth participants were more worried about contracting the disease in that it is known to disrupt a person's goals in life and one's ambition to move towards set goals. A small proportion of youths expressed fear of contracting the disease in that they would be rejected by their families and friends. Youths from rural areas expressed fear of contracting HIV saying that this would make them unproductive and also make them a burden to their families. They also expressed fear that their financial burden would increase. Another fear of being infected with HIV expressed was the possibility that a person would be rendered poor. The following are remarks by urban and rural male youths.

If found positive to HIV, it means that with time you will be weak and you will not be able to work on your shamba (farm). If you have a family they will have to depend on others. You will also be a burden to your own family and the society too. - Rural male Youth

Some adult participants expressed the fear that if they got infected they would be rejected by the members of their families and also by friends. This was particularly commonly mentioned by young adults. Another fear expressed by young adults was that the disease is usually associated with promiscuity and therefore if infected they feared that they would be labeled promiscuous. 
It is terrible to be found HIV positive; this would mean that someone's life has to be rearranged; your visions in life are gone. People will no longer be able to associate with you well-Urban male youth.

You see, the issue is that people always think that AIDS is for those with loose morals. I would not want to be looked like that- Urban male youth

A small number of the participants were of the opinion that people of their age and sex are not worried about contracting the disease. Some of the reasons given for not worrying included the fact that AIDS is a disease like any other and contracting it may simply be bad luck; and that while there is no cure for the disease at least there exists some sort of treatment that allows people to live a good life even after contracting the disease. A small group of people, mainly drawn from urban youths, were of the opinion that AIDS is like an accident, which you cannot predict, and therefore there is no need to worry about it. A good example of this opinion are remarks by two urban male youths:

Look, it will never be possible for you to fully protect yourself from the infection. For example every time I go out with my girlfriend, I trust that she has been faithful; I have no way of proving otherwise. You just have to be lucky not to contract the disease-Urban male youth.

It is unthinkable that you can get the infection from the very people who are meant to protect you. I have heard of people who got infected while using public health facilities. Accidents do occur and we have no way of protecting ourselves from them. Only God can -Urban male youth

\subsection{Attitudes and Perception towards testing}

To assess participants attitudes towards HIV testing, participants were asked if they thought people like them would want to know their HIV status and also state reasons as to why they would or would not want to know their status. Regarding this, participants expressed varied opinions across all categories of age and sex. 
Respondents in favour of testing gave varied reasons for wanting the test. Participants in the youth groups felt that testing for HIV is good because it helped a person to protect themselves against the diseases and also be able plan for their future with a bit of certainty. Another small number of participants felt that if people knew their HIV status they will avoid infecting others. A common feeling by youths is that testing for HIV would enable them to live a longer life and be able to plan accordingly, for example when they want to get married as indicated in the remark below.

People who know of their HIV status are able to plan for their future. At least you are sure of your health status, you do not need to worry about imminent death but you concentrate on doing what you have to do to enable you to have a better life- urban male youth

Moreover, youths said testing was important in that a person attains a sense of being safe if found negative and for those who test positive it could be an opportunity to educate others on remaining negative as indicated in one youth's remark below.

When you are tested of you tend to get more information than otherwise, you feel safe you are able to educate your colleagues as pertains to this disease-rural male youth

Regarding the same, adults had varied reasons as to why someone should or should not take a HIV test. A number of respondents thought that knowing one's status helps in planning for the future and particularly if one had in the past been exposed to the disease through risky sexual practices, such as unprotected sex as expressed in the following remark by one adult female.

Some of us may have trodden the wrong paths... we need to know how safe we are for us to be able to plan for our life- urban adult female

Among the rural adults living happily was the common reason given for HIV testing. Another reason given as to why the HIV test should be taken by adults living in urban areas is the fact that people would want to know if they are 'healthy' or not (where health implies a HIV negative status) so that they do not end up paying a lot of money for a Visa that will not be granted if found HIV positive 
and also the fact that some employers required the test while employing as expressed in the remark below.

It is important particularly if you want to travel. Many of the embassies require that you take a comprehensive health test. This is expensive and if you knew your status before this could save you a lot of money. - Urban male adult

Some of the reasons given as to why people would not want to test for HIV included the fact that people who test positive may be rejected by their family and friends, they may live a stressful life just by knowing their status and that people who test positive to HIV may commit suicide and that they will have a reduced productivity by mere knowledge of their status. Examples of these views are expressed in the following two remarks by an adult male and female.

One reason as to why I think people opt not to take the test is the fact that they do not want to be rejected by the society, if you are known to be HIV positive people will definitely not treat you as normal.- rural Male adult

If you know you are HIV positive you will have stress, your productivity will go down soon you will be laid off- Rural female adult

Asked to give an opinion on whether HIV positive people discusse their HIV status, most participants were of the opinion that that HIV positive people do not discuss their status. For the few who do, they were said to discuss it with their health care providers, family members, close friends or with other HIV positive people; a belief especially prevalent among female youths and adult groups. As to why they do discuss their status there was a general belief that they do this in order to get support from healthcare workers, the family, friends and other HIV positive people. Among the adults there was a general feeling that those HIV positive people who discuss their status in public do this in order to build HIV awareness. This is captured in the following remarks by adult males

I do not think many people discuss this but I once had a close friend who confided in me, he had to because he did not have anyone else to talk to. HIV positive people need support from us as friends and family. - Adult urban Male 
Yes people discuss this to educate others on the disease but these are few people who are courageous. - Adult urban Male

Asked why they think that HIV positive people do not discuss their status, participants had varied views. Among the adult groups, the main reason given as to why HIV positive people do not talk about their status is the belief that HIV/AIDS is "a shameful disease" associated with people of loose sexual morals. A prevalent belief among the youths is that people would be ostracized in the community and therefore they prefer to keep it to themselves. This opinion was expressed in the remark below by an adult female

AIDS is a sexuality disease. The society has taught us that matters of sex should only be discussed in the bedroom. It is counted as shame to talk about it in the open. - Adult female

Female youth expressed a belief that HIV positive people do not discuss their status for the fear of being the subject of gossip among their friends that may lead to a loss of reputation in the community, loss of confidentiality and increased isolation and rejection as expressed in the following remark by a female youth.

Who would want to subject themselves to gossip, definitely they will lose dignity if they did that. They do not want o be the subject of the day. - Female youth.

\subsection{VCT awareness}

Regarding participants' awareness of a place where they could take a HIV test, all the participants were able to mention at least one place that they could go and take the test from. Asked how they came to learn about these places respondents had varied answers. These included personal referrals, brochure and posters, radio, television, referral by community healthcare workers and barazas (community meetings).

On the expected benefits for someone who undergoes HIV counselling and testing two common themes emerged. The first theme and the most prevalent is the perception that people who go through HIV counselling and testing receive some kind of support that helps them to either stay negative if uninfected, or to live positively if infected. Some of the benefits mentioned alongside this theme for 
people who test positive to HIV included getting advice on bodily care, getting advice on nutrition, getting advice on family planning and getting advice on available treatments regimes for the disease. For people who test negative to HIV, participants mentioned that they can expect to get advice on family planning, safe sex, and more HIV education. This is captured in the following remark by an adult female.

Well there are a lot of benefits but it depends on which side of the river you are, if you are infected the doctor (actually means a Counsellor) will help you to know how to take care of yourself, what to eat where to go for treatment among other things. If you are not infected with the virus, at least you will have more confidence in yourself and you will learn how to take care of yourself so that you do not get infected.- adult female.

Some participants believed that once a person knows his or her sero-status, whether positive or negative, they learn some methods of protecting themselves and others from the disease. Several respondents cited condom use as an important component to this behavior change. This was clearly captured in the following remark by a young male participant.

If someone knows how his/her health is it is a step in protecting him/her self from the disease. I expect the Counsellor will teach them on the best way to do this. How to have sex safely without endangering other people. - Young male

Among adults, several respondents thought that counselled clients can then counsel others. This response was particularly prevalent among adults. The quality of counselling was also an important benefit to some adult respondents, such as preparation to receive results and, for a few 30-39 year olds, receiving advice on reproduction issues.

When you are counseled, you get proper information which you can pass to young people who depend on you for direction and also you can help your colleagues.- adult man

The second theme that emerged on the expected benefits is the fact that knowing someone's HIV status would eventually lead to reduced HIV infections in the general population. Most of the 
respondents were of the opinion that VCT increases a person's knowledge of the disease which helps in protecting themselves better and in the long run leads to a reduced prevalence in the general population. The HIV counselling component of VCT on the other hand was expected to aid in personal behavioural change among the respondents, a thing that was said to translate to reduced rates of HIV /AIDS prevalence. The following remarks by an adult male participants shows these beliefs.

You see if everybody knew their status and they are not malicious, they would protect others who are not infected. This would reduce the burden of disease in our community-adult male

Some youths were, however, of the opinion that people who test negative to HIV may have a reinforced false belief that would make them engage in risky sexual behaviour which in turn increases their chance of contracting HIV and hence increases the prevalence of the disease in the general population. This is expressed in the following remark by one youth male participant.

To me I see it in the other way. People who have gone for VCT and tested negative can start thinking that they are untouchable by the virus, they may continue in their behavior, if they do then I don't think what he is saying would be true..... We would actually in that case, have more people infected than we already do.-male youth

Asked which people would be interested in taking an HIV test, the majority of the respondents, irrespective of their age, sex and geographical locations, felt that basically everyone is interested in knowing their HIV status. The few who felt that not everybody is interested in taking the test argued that people who are sexually active may be more interested than those who are not sexually active. This belief is captured in the following statement by a young female

I think it depends; people who engage in sex may want to know if they have been infected. If I don't engage in sex then why would I doubt myself? - Young female 
It was also commonly mentioned that youths are mostly affected and should therefore be on the front line in knowing their HIV status. A few people thought that health care workers could be interested in that they come in to contact more often with sick people.

Another category of people mentioned that could be interested in taking up the test are the people who have recently divorced or people who are courting and would want to get married soon. Older respondents and particularly women thought that VCT would help strengthen spousal relationship if there was mistrust between couples. This is captured in the following remark by an adult female.

You see, this thing would be helpful to families. Where both husband and wife know the status of the other it would boost trust, the problem is only that our men do not agree to go with usadult married female

Asked whether people like them (the respondent) would be interested in taking a HIV test, the majority of youths were open to the idea compared to other groups. Adult respondents were more interested in information about the disease rather than taking the test so that they can use that to help young people in their families.

This thing is very new to us, we do not know many things about HIV, if we go see the doctor, (actually means a counsellor) I would be taught many things. I will be made aware so that in future when my friends and my children come to me, I will be able to direct them well. Right now I have nothing about it to offer

\subsection{Hindrances to utilization of VCT service}

Regarding hindrances to VCT utilization, frequently mentioned impediments included inaccessibility in terms of distance to their homes, lack of privacy, apprehension about a positive test, fear of being stigmatized, transport cost to the VCT centre, and location of the VCT centre within the building in relation to other services offered at the health centre. The following accessibility issue was expressed by one adult male living in the rural area. 
Look at it this way, the nearest VCT centre to our home is at Nyojoro (name of a trading centre). This is ten kilometres away. To access it I would need to take a matatu (mode of public transport) because if I have to walk I will take a whole day, I have other work to do. rural adult male

The fact that the disease has no cure was also seen as an impediment. Participants saw no need to get tested if they will get no cure anyway as the following young male living in the rural area remarked.

Even if you are tested and found positive, nothing much will happen, it is just in vain, you will not be cured - young rural male

Among the adult respondents' work load was the main hindrance to VCT utilization. The need to attend to other responsibilities presented them with less time to visit the centre for the test as suggested in the above remark by one adult male living in the rural centre.

Fear of what their parents would think if they found that they had gone for a test was also said to be another hindrance among the youths. One female youth stated the following.

I do not know, but I am not sure what my parent would think if they found out that I had attended a VCT. Perhaps if I am free with them and they gave me their support I would be able to do this. -Female youth

Women reported that many people would be willing to go for a test if the services were free or affordable. The issue of the location in relation to their home location also came up. The issue of having to get appointments to attend a service was also seen as a hindrance. One female rural resident participant expressed the following

You see my schedule is such that I wake up early in the morning, prepare my kids for school, milk the cows, take the milk to the sale centre, go to the farm, prepare lunch for my children go to the farm again until it is late in the evening to come back just in time to do the milking again. If you look at this schedule it is impossible for me to get a lot of time in order to 
observe the strict appointment needed for the test. I tried in the past and failed. I am still waiting for the time I will be available.-adult female rural resident

Another hindrance to take up the test was lack of close friendship among the youth. Having friends to walk with to the VCT clinic was said to be a motivation as expressed by the following remark by one female youth.

Me I would say that some people, me included, fail to go for the test because we do not have friends who we can go with at the centre. It would be scary to go alone. If my buddies supported me and agreed to go with me perhaps I would take the test. Female youth

There were also concerns about the quality of the service and attitude by the providers. A Few participants cited apprehension that counsellors may be unfriendly, are judgmental and "boring". One adult female living in the rural area stated the following on this.

One time I had taken my first born to the hospital. I did not have enough nappies to change the kid in as I had left the house in a hurry. The nurse was not very kind to me; she called me all sorts of names accusing me of being lazy and ignorant. I fear this are the same type of people that are running VCT facilities. We should have friendly people running the centres. I do not want ever to go through the same again and especially when it is about HIV/AIDSadult rural female.

A few respondents feared that they could get wrong results from the test.

\subsection{Motivations toward the utilization of VCT services}

Regarding motivations to taking the test, participants had varied ideas. Among the participants, whether married or not, educating people on HIV/AIDS and stressing the importance of knowing one's sero-status would motivate them to go for HIV testing. The youth thought that the location of the VCT centre in relation to their home coupled with the location of the counselling room in relation to other services offered at the centre could be a motivating factor. Some youths also believed that free, private and closely located VCT centres would attract more people to take the test. A few 
youths suggested parental support to be key in deciding as to whether to go for HIV test or not. The above views were well captured in a remark by one female youth:

You see, our local VCT is about $10 \mathrm{~km}$ away, If I need to get a test I have to walk for all that distance and that will take a lot of time, it means then I have to get permission from my mother and I do know how I would explain this. She will automatically know that I have been having sex. Female youth

There was a feeling that if VCT was marketed properly, whereby people are educated about HIV together with other common health problems like malaria, people would be more likely to take the test than when HIV testing is promoted alone. There was a feeling that by promoting HIV alone it was seen as an extraordinary disease which, in the process, promoted fear in people, as expressed in the following remark by one adult male.

I believe people already have an attitude against the disease. The way adverts come about in the television is usually very scary. People do not believe that it is a normal disease; they put pictures of very thin people, dying people. This makes people opt not to take the test. They would rather die without knowing than to imagine they will be that thin, that miserable. Adult male

While it is a common practice to offer the service for free to all the willing people, respondents felt that this was not really free in that they needed money to travel, as expressed in the following remark by one adult male residing in the rural area.

We are told the service is free but they do not consider that I have to travel to the centre which is miles away. I am also aware that good centers charge for the service, why can't the government have a VCT centre in our shopping centre nearby, this would be very advantageous to us, it would save us a lot of time and money......-male rural adult

Other motivations to take a HIV test mentioned included lifestyle change, such as marriage, new sexual partner, pregnancy or taking a new job and the need for adults to plan for their children's 
future or where they think one of them is unfaithful. Moreover, the respondents felt if people were educated on how the anti retroviral drugs work, they would be motivated to take up the test. They felt that misconception on ARV drugs and HIV disease drives people away from testing as expressed in the following remark by one adult male urban resident.

Me I feel that people do not understand how these drugs they say are available works, if they are shown how the drugs work perhaps they will find the wisdom in testing-urban male adult.

Finally, some respondents from all age groups thought that incentives like money, t-shirts and drinks should be offered as an encouragement to get HIV testing.

\subsection{HIV testing and Behaviour change}

As to whether an individual's behaviour might change as a result of knowing his/her sero-status, participants had divided opinion. The majority of the participants were of the opinion that once tested people would definitely act in some ways that would either increase the rate of infection or decrease it. Some people felt that if people knew their status to be positive they would take care of themselves and their partners while others felt that this would make them commit suicide or even infect others knowingly in revenge. One urban resident adult male stated the following.

In my opinion, if people knew that they are HIV positive, they are likely to change their behaviour. Regrets would set in and probably this will make them change their sexual behaviour. Nobody wants to die quickly, they want to take care of themselves and others too.adult urban male

Of those who test negative, many respondents felt that they would change their behaviour; in order to preserve their HIV negative status. As already mentioned, a small group of youth felt that they would not change their behaviour since they would think they are immune to the disease.

\subsection{VCT promotion}

The most popular mode of VCT promotion noted by the participants was mass media (radio, television, newspapers, posters, pamphlets and magazines). Other modes of preferred for VCT 
promotion included Youth fun centers, youth groups, and fun days. Barazas (public meetings) and other public forums were the more preferred way of VCT promotion for the rural residents.

On the type of information the participants would prefer to get when VCT service is promoted, opinions were varied. These included information on the VCT location, the operating hours, information on any charge and information on other services offered at the centre. On the HIV test itself, participants expressed the desire to get information on the nature of the test (how it works) the procedure that a client goes through while taking the test, and how the results are interpreted. Other type of information desired included information on HIV prevention, and treatment. A few people mentioned that they would like information of other sexually transmitted diseases to be included in the package.

The respondents were asked to describe the type of service they would expect when they go for HIV testing at a VCT centre. Participants' opinions varied on this. The most common response to this question in all the categories was counselling and HIV testing services. Young people groups expected information on HIV/AIDS control and prevention such as information on condom use as well as information of other sexually transmitted diseases. Adult respondents expected that on top of HIV counselling they would be educated on how to counsel their family members who may need their help.

Regarding the desired mode of service, participants were asked to state how they would like to be served at the centre. The most frequent response by the participants, regardless of their age, sex and geographical location, was related to issues of quality. Participants felt that they would be more comfortable going for the test if they were assured of the quality of the service. Other frequently mentioned issues of service included assurance of their confidentiality, polite and respectful communication by the Counsellors, and courteous treatment even with an HIV positive status, private service and rapid results. The issue of timeliness by the Counsellor in regard to appointments was also mentioned by a number of people. Respondents particularly expressed displeasure with waiting in the queue for a long time. All age groups expressed preference to be counseled by people of their own age and sex. 


\subsection{Findings from Key informants}

Regarding the training background, the majority of the counsellors had undergone some training ranging from a basic counselling certificate to a diploma in counselling. For with most their training experience ranged from one year to ten years.

On the number of clients seen by the Counsellors daily, all the key informants reported to being able to see an average of 20 clients every day. Two of the respondents reported to having to frequently turn away clients due to lack of capacity and time to see them.

Asked about the major concerns that the clients have when coming for the test, respondents cited apprehension of a positive HIV test result. A key informant stated the following.

I once had a woman client who was so fearful that she is already positive, because she thought that her husband was not faithful. I took a lot of time to talk to her to allay this fear; many of them have this fear that they are infected even before they have taken the test.- Key informant Nyojoro VCT centre

Other fears expressed by the clients cited by key informants included fear of spouses not agreeing to come for the test and the possibility of getting wrong results.

Regarding the accessibility and convenience of the service to the intended users, Key informants were of the opinion that there is a need to adjust the current service delivery time whereby it is offered between $8 \mathrm{am}$ and $5 \mathrm{pm}$, to allow easy access for working people during lunchtime, early evening and weekends, a sentiment echoed in the following statement by key informant in one VCT centre.

......thirdly I would make sure that this service is offered even on the weekend because there are people who are working; others would want to be served even after five in the evening because this is the time they are available. I would make sure that the service is offered for as late as $6 \mathrm{pm}$ and over the weekend. - Key informant

One key informant suggested a need for additional spaces in the counselling centre for other activities such as providing a supervised space where children can play to enable less interrupted 
counselling session and where clients are kept comfortable. Other activities suggested included youth friendly centre whereby youth activities can take place; a sentiment echoed in the following comment by a key informant at a VCT centre.

About restructuring, VCT should be given a good plan whereby there is good flow of clients. Like you see here patients are mixed, sometimes others do not want to be seen coming for VCT. If there was that good planning it would be possible to put a reception, and a place where the clients waits comfortable with reading material and a television set. Young people may need additionally facilities. When I was being trained I was told it's good to have it to keep the client busy and also put educative programmes running.

Asked to give to give some of the areas that need to be improved to make the service both effective and efficient, supervision, opening times, good planning of the building where VCT service is to be located as well as good budgeting were mentioned.

One thing that personally I think it is not done well is about supervision. It is started quite late. For me supervision is important. Many Counsellors are doing wrong things, the Counsellor is alone in the room and can do anything. Whether they do the correct or the wrong procedure no one would know. I would recommend an observed practice. The Counsellors can actually observe each other in practice so that if one person is failing the can correct each other. Supervision is one of the things I would insist on. It should be that if one does not go for supervision then they should not practice.

Moreover, data management was viewed as not aiding the VCT service at all despite the continued collection of the data. The reason for this was said to be the fact that nobody ever analyses the data and also because the data do not capture what is important for the centers in question

Another thing is about the data. I think there is too much data; there is quite a lot of it that have discrepancies. You find like now for example the data forms that we have is not applicable to children and polygamist, some of them do not capture anything. And then by the end of the day why are we collecting that data? it is not even applicable for our own report. 
If we improve on this data it can be analyzed and help us collect statistics and may be change some policies

Regarding linkages to other services, all key informants cited the existence of a comprehensive care centers at the location of the site. All of them referred the patients who test positive to these centers unless the client wanted to go elsewhere.

We have a comprehensive care; we do have all the facilities needed to take care of the patient. We have a model of care which is comprehensive. We also have support groups. However the client has an option to go elsewhere if they like

In general, qualitative finding is that the level of HIV/AIDS knowledge among the respondents is high among the respondents. However, a few respondents have expressed misconception relating to the infection and the VCT service. Consequently, the respondents assume that they will test positive to the disease, and therefore be forced to face severe personal trauma and societal stigma/discrimination if they take an HIV test. This apprehension has greatly overshadowed the benefits that they could accrue in knowing their status. Nevertheless, majority of the respondents want to take up the test but both social and health system barriers such as gender inequality, the cost of taking the service, service operational hours, accessibility; misconceptions about the disease are barriers to the utilization of the service. 


\section{Chapter six}

\section{Discussion}

\subsection{Introduction}

This chapter provides a discussion of the findings. It starts with a discussion on the demographic characteristics of the respondents after which HIV awareness, HIV risk perceptions, VCT awareness, attitude towards testing; and motivation and Barriers to VCT uptake are discussed. The chapter ends with a conclusion and recommendations.

The purpose of this study was to describe the dynamics of VCT uptake among rural and urban communities of Nakuru district, Kenya. It is now acknowledged that HIV voluntary counselling and testing are entry points to HIV related care and prevention services and that it provide opportunities for people to reduce their risk of acquiring or transmitting the disease. The study was undertaken due to the fact that although the VCT services are free in the country, the uptake has been very low. According to the Ministry of Health, less than 20 per cent of Kenyans know their HIV status at the moment. Moreover, an estimated 1.2 million HIV-infected Kenyans do not know that they carry the virus and therefore do not receive any sort of HIV-related care (MOH 2008). Some aspects of the VCT service, such as the performance of the counsellors, clients' attitude towards testing, HIV stigma, VCT centres' operating hours, accessibility, among other aspects were expected, from previous literature, to play a significant role in VCT uptake and these formed significant components of the study tools.

\subsection{Demography}

A majority of the respondents responding to client exit questionnaires were aged 16-35 years. This was similar to other studies (Fylkesnes \& Siziya, 2004; Jereni \& Muula, 2008; Ma et al., 2007; Morin et al., 2006). This could be explained by a perception that young adults feel more at risk because of their own activities compared to older people, especially in relation to sexual behaviour. It is also possible that young people have more comprehensive information sources than older adults. Equally, it is also plausible that older participants were less willing to accept VCT for fear of stigma or unfamiliar practices than were the younger people. Indeed this apprehension was constantly expressed during the focus group discussion with adult male and female participants as one of the main reasons why they had opted not to take the test. 
More males than females attended VCT. Studies on VCT uptake by gender provides mixed results with some research indicating a higher uptake by males than female (Reilley e tal, 2004, Adamasu \& Fitaw, 2006) and others (Olewe et al., 2008) indicating a higher uptake by female than males. The inconsistency in these studies might be due to differences in target populations, service delivery, geographical, and social-cultural context; and adjustment for confounding.

A possible explanation of this uptake imbalance in the current study could be in gender roles and relations which limit control by women in matters regarding sex. Uptake of VCT by female clients is influenced by the power women wield within a sexual relationship. In Kenya, just like any other African country, women are ranked lower in the gender hierarchy. Married women are still often subject to their husband's authority and may therefore have to get permission from their husband, to go for a test. This was regularly cited during the focus groups discussion with the married female participants as one of the reasons as to why they had not taken the test. Being an unmarried female does not help the situation either as gender inequality permeates the larger society, whereby an unmarried female is expected to get permission from the male partner or in case of a minor, from the father. A study considering the role of men in the prevention of mother to child transmission of HIV (PMTCT) conducted in Botswana by Kebaabetswe et. al. (2003) revealed that men did not support the idea of their wives/partners being tested without their permission.

Females may refuse VCT in order to avoid potential negative consequences in case of disclosure of a positive HIV test result. A study by Gaillard et al. (2000) showed that $68 \%$ of HIV positive women in a resource poor setting in Africa did not inform their sex partner, mainly for fear of their reaction. Other studies (Campbell, Marum, Alwao Edyegu, Dillon, Moore \& Gumisiriza 1997 Grinstead, Gregorich, Choi \&Coates, 2001) have also reported such disclosure being met with such consequences as violence, the breakup of marriages, being neglected or disowned by their families, loss of security, shelter, food, relationships; and even murder.

Further, in Kenya, HIV or sexually transmitted disease in women is associated with a higher level of stigmatization associated with premarital and extramarital sexual activities (Moss W et al, 1998). This further compromises women's ability to seek HIV or sexually transmitted disease testing and care (Wu Z, 2007).

Similar difficulties in accessing VCT services exist for unmarried people whose VCT-seeking is especially complicated by the stigma associated with premarital and extramarital sexual activities. 
In the light of this observation, targeting female and single people for HIV/AIDS health education and addressing gender inequality should be made a priority in public health interventions. Interventions need to be tailored for this population to increase their awareness of HIV risks, reduce misconceptions, and promote HIV testing among the populations. Moreover, these findings suggest interventions focusing on participation of both spouses in counselling to help VCT services to obtain their objectives. Studies (Okonkwo et al., 2007, Baiden et al., 2005, de Paoli et al., 2004 and Creek et al., 2007), have shown that males spouse participation increases women's willingness to be tested for HIV. This willingness could be by male accepting testing simultaneously with their partners, by accepting to accompany their wives to the testing centres, or by males taking the test earlier than their wives.

Marital status can be an important risk factor when exploring patterns of HIV transmission in a population and therefore should be taken into consideration when implementing HIV prevention programmes. Regarding this more clients in married/ living with a man/woman as if in a married relationships sought VCT services than those in single, widowed or never married categories. This is different from a study by Irungu et al. (2008), in the same area which showed a low uptake of VCT by married/living together. A probable explanation for this is that there was an aggressive promotion of couple HIV testing and counselling in reaction to a study's findings (NASCOP, 2008), which found a high prevalence of sero-positivity among monogamous couples. This may therefore imply a success in this particular couple testing promotion.

The current study's finding on the service utilization by people of other marital categories raises concern. While widowed/divorced has more than tripled since 2003 (NASCOP, 2008) only few of them $(4.4 \%)$ sought the VCT service. This is especially relevant in the current study since people who have ever been widowed, divorced or separated have high HIV prevalence at 17-21 percent (CBS, 2003). One hypothesis is that partners of such women are likely to have departed them due to sexual related matters or died from HIV-related illness after years of infection. This therefore means that partners are potentially exposed to HIV for several years before their partners leave or die. VCT programme targeting this population category is more likely to reduce new infections and also reduce morbidity related to HIV.

Most of the participants responding to the client exit questionnaire in the present study had at least primary school education. Good education is important in creating awareness of HIV and 
promoting VCT services. Studies (Herek et al, 1998, and CDC, 2000) indicate that people who have little education are more likely to have little knowledge about HIV modes of transmission, are much more unlikely to take up the test; and also more likely to hold discriminatory attitudes than those who have high education. Conversley, people with good education are more likely to have correct knowledge about HIV, less likely to hold negative attitude towards people living with HIV and are more likely to go for a HIV test.

There is however conflicting associations between HIV test and education. Several studies (Matovu et al. 2005; Mpairwe et al. 2005; Thior et al. 2007, showed reduced VCT uptake among educated individuals, Kiarie et al. (2000) and Nyblade et al (2001) found no association between HIV testing and education, while Gage \& Ali (2005), Hutchinson \& Mahlalela (2006), Perez et al. (2006) and Sherr et al. (2007) showed an increased VCT uptake among educated individuals. The fact that they used different population groups in their studies and the fact that they do not show how they controlled the confounding factors may explain these inconsistencies.

A majority of the participants responding to the client the exit questionnaire were protestant. Religion is important in that highly conservative religions indirectly discourage people from taking the test. In this study only a few people were of catholic and Islamic faiths. A possible reason is that these two are highly conservative religions which emphasize fidelity and pre-marital abstinence as a matter of piety, therefore were more stigma associated with attending VCT centre for the test. Moreover it may also be explained by the negative attitudes towards condom use and other contraceptive methods offered during VCT services which go contrary to their teaching.

Farmers and people in business occupations made the majority of the respondents who attended the VCT centers. Students and people of professional occupations comprised a very small proportion of those who attended. A possible explanation for this could be convenience of the operating time. The VCT centres open doors for the clients at 8 .am and close down at $5 \mathrm{pm}$. This may be convenient for farmers and businessmen who are self employed but not for students and professionals who have to adhere to certain time schedules. In fact, key informants noted that the majority of professionals do not attend the test due to inconvenient service operating hours that coincide with their working hours. These findings suggest a need to restructure the service so that they remaining open through the lunch hour, late evenings and weekends, to accommodate people who may have work or other obligations that prevent them from accessing services during normal business hours. 


\subsection{HIV Awareness and Risk Perceptions}

A majority of the respondents completing the structured questionnaire exhibited a high level of HIV/AIDS knowledge in the six domains of knowledge that included awareness of the disease, the cause of the disease, mode of transmission, the disease treatment, risky behaviours, and preventive measures. Equally, most of the people who participated in the focus group discussions were familiar with matters relating to HIV/AIDS, and indeed admitted to ever having a discussion on the topic. This is similar to other studies (Njue, C et al 2009, NASCOP, 2008, UNGASS 2010) which reported a high level of knowledge among the respondents.

A possible explanation of this is the fact that there has been a lot of HIV/AIDS related work in this community and also the fact that this was a client exit interview, meaning that some of the knowledge could have been gained during the counselling process. A bivariate analysis using Pearson chi square test on knowledge as the outcome of interest against social demographic characteristics of the respondents including age, sex, education level and occupation of the respondents and occupation showed no significant results on all the six.

Knowledge has been cited as an entry point in the initiation of behaviour change (Njue, $\mathrm{C}$ et al 2009). Since there is neither a treatment nor a vaccine against HIV and AIDS, behavioural change provides the only protection against infection. Efforts to prevent or reduce risk of HIV infection through behaviour change begin with an understanding of the determinants of risk behaviour. Several models have been proposed to explain HIV-related risk behaviour for this; prominent among these being the AIDS Risk Reduction Model (Catania et al., 1990) and the Information- MotivationBehavioural Skills model (Fisher and Fisher, 1992). Both models identify knowledge as an important determinant of risk behaviour. Accordingly, most intervention programs (VCT included) provide information about HIV-related transmission and prevention to help participants to reduce their risk of infection. While the researcher notes this high level of HIV/AIDS knowledge, it is equally important to note that a small percentage of the respondent depicted misconceptions on the six domains which needs to be addressed as they may lead to risky sexual behaviour. In this light, community Health education should continue among all the community groups as there are no identifiable groups with lower level of knowledge.

Regarding HIV risk perception, the majority of respondents $(70.9 \%)$ responding to the structured questionnaire felt that they were at risk. Equally, most of the participants in the focus group discussion expressed some perception that they were at risk of contracting the disease. Marital status 
of the respondent was found to be significant in determining whether they felt at risk or not. Single, divorced and widow/widower respondents were less likely to feel at risk than their married/living with a man or woman as if married counterpart. This is different from findings in other studies (Shisana, et al.,2004, Njue, C et al 2009, Catania et al., 1990) which found the HIV risk perception not to differ between married and unmarried people. A possible reason for this inconsistency could be the highly publicized study findings mentioned earlier, (NASCOP, 2008) which indicated a high prevalence of sero-positivity among monogamous couples. This could have made married/living with partner feel more vulnerable to the disease compared to their single, divorced and widowed counterparts.

\subsection{VCT awareness and Perception towards testing}

Participants depicted a high level of awareness of VCT services. All the participants were able to mention at least one place one could go for a test. Equally participants expressed a positive attitude towards testing, whereby there was a general feeling that taking a HIV test was seen as beneficial. However some of the participants were not willing to take the test citing various things that included fear of wrong results and inefficient rude counsellors. Studies have shown that service encounters, whether directly (i.e. by actual utilization) or through proxy (i.e. through interaction with people who has utilized the service), can significantly influence clients' attitudes towards the service (Parasuraman et al., 1994, Btner, M.J.,1990). This in turn influences their utilization depending on whether they perceived the service to be of quality or not. To explain how this comes about Holbrook and Corfman (1985) introduced two concepts: client satisfaction and client attitude. According to them, client satisfaction refers to a client's evaluation of a specific transaction while a client's attitude corresponds to a global evaluation of the product/service and which is not objective. Consequently, the tendency by non-tester to depend on the general public health facilities which are generally poor, may have made them create a negative attitude towards them. In turn this could have led to poor utilization of the VCT facilities since most of them are offered in general public health facilities. Following this argument, improving the general public health services which have been associated with poor services could also lead to an increased VCT uptake. Alternatively, delinking VCT services from the government operated public health service may redeem its image among the targeted consumers and hence lead to an increased uptake. 


\subsection{Motivation and Barriers to VCT Uptake}

There were clear age and gender differences on the motivations and hindrances to the utilization of VCT services. This was expected in that different community groups have different issues that may work towards motivating or hindering VCT utilization.

However, common among the participants regardless of their age and gender, were apprehensions of a positive test and fear of being stigmatized. These barriers were much more common themes among non-testers (focus group discussions' participants) than they were among those who had taken the test (respondents to the structured questionnaire). Fear of positive results, sudden death and losing dignity has been showed to hinder VCT utilization (McNair,1998). While there has been a lot of HIV education in the community these findings suggest that HIV misinformation is still prevalent among the community members and therefore more education is requred. Moreover providing extensive community outreach and post-test support services as part of a comprehensive VCT program may be helpful.

According to the Key informants the counselling process included offering information on how the testing is done and how results are interpreted. At the same time, other information is also given which includes information on how the disease is transmitted, how the disease is prevented, and the available treatment regimes. The main focus of this information is enhancement of personal responsibility, a tactic that discouraged certain behaviours that could put individuals at a risk of contracting HIV/AIDS. While this model may appear to be the most effective approach to encouraging individuals to be aware of the potential consequences of their actions and to take responsibility for changing their behaviour to protect themselves, it fails to address adequately the other aspect of HIV risk: that one's partner may constitute a threat to one's health and life. This, for example, was expressed by some women participants in the focus group discussion who said they had not taken the test because their husband/partners had not 'given them permission' to do so. Others expressed frustration because they had no way of controlling their unfaithful partners. Moreover, youth participants in the focus group discussion felt that HIV was more of an 'accident' as they had no way of ensuring that one's partner has been or will remain faithful.

Information that stresses the importance of personal decision- making in HIV prevention may unintentionally promote a negative perception of those who test positive to the disease. This pattern is worrisome because individuals with an undesirable condition are generally subjected to greater stigma when they are perceived to be personally responsible for their situation. While the current 
information is useful in addressing personal risk, there is a need to re-orientate VCT services so that information offered addresses the external HIV risk for example by encouraging couples to come together for HIV counselling and testing. Moreover, more needs to be done so that VCT sessions equip testers on ways to negotiate for safer sex with their spouses and particularly women.

Inaccessibility and the inconvenience of service operation hours were other barriers mentioned. To some, and particularly adult working group, inflexible working hours made it impossible to take up the test. Additionally, the cost of transport to the VCT centre was also mentioned as impediment. The fact that some VCT centres were located far from the target population increased the cost of transport much more than the participants could afford. Rigid service operation times coupled with transport difficulties limit the number of people seeking VCT from established healthcare settings (Asingwire 2004; $\mathrm{MoH} \&$ ORC Macro 2006; Morin et al. 2006; Yoder et al. 2006). A possible solution to this problem could be re-orienting the service from the traditional mode whereby VCT is made available at the government health centres, to more pro-active modes, such as mobile VCTs and home based HIV testing which can be offered at the nearest market place and at client's home setting. This will help to overcome these and other social barriers which have been associated with low uptake.

While majority of the respondents to the client exit structured questionnaire expressed satisfaction with the level of privacy during the counselling and testing process, it was one of the major things mentioned by the non-testers (Focus group discussions participants) as to why they had not taken the test. Concerns about confidentiality have been found to represent an important factor reducing acceptability (Irwin et al. 1996; Kim et al. 1997). People seem to place a high value on privacy; that needs careful thought when VCT is offered. Services that maximize the autonomy of the client appear to correspond well with high demands. An important underlying reason for the low response to clinic-based VCT is likely to be associated with confidentiality. In this study, based on the focus group discussions, I postulate that factors such as the likelihood of meeting someone known to the individual at the local clinic and fear of breach of confidentiality by clinic staff were factors that could influence acceptability negatively.

AIDS related stigmas create barriers to seeking VCT. To asses this, respondents to the structured questionnaire were asked two questions touching on discrimination and their willingness to take care of somebody who is HIV infected; and an open question relating to the same was asked of the 
participants in focus group discussions. The majority of the respondents to the structured questionnaire were willing to take care of a HIV positive patient signifying low level of stigma. A small percentage $(<8 \%)$ however of those who tested reported HIV/AIDS stigma. On the contrary qualitative data from the focus group discussions yielded several aspects of HIV stigma including negative perceptions of people living with AIDS, a sense that people with AIDS could feel ashamed and guilty. They believed that people who contracted the disease lose their dignity and were likely to be looked down upon by other members of the community.

These findings are consistent with other studies (Fortenberry et al, 2002 and Stall et al., 1996) which showed that HIV/AIDS-related stigma is higher among the people who had not tested compared to those who had taken the test. While it is true that other aspects of VCT service delivery influence VCT uptake, the stigmatizing of HIV noted by focus group discussions' participants could play a significant role in the service uptake, and there is a need therefore to increased HIV education among the community members to fight stigma. Studies have shown that in a community where HIV stigma is prevalent people tend to avoid taking up the test (Chesney and Smith, 1999; Eisenman, Cunningham, Zierler, Nakazono, and Shapiro, 2003; Fortenberry et al., 2002; Stall et al., 1996). This is because HIV related stigma foster social isolation and discrimination against people with HIVAIDS and therefore people would rather not take the test if they perceive that it will endanger their position in the society. In this sense it becomes a barrier not only to prevention of HIV, but also to care and treatment of people living the disease.

Fatalism, a feeling of helplessness in the face of an incurable disease, was expressed by a number of non-testers. These individuals felt no need to know their HIV status without any possibility of cure. These findings are similar to other studies (Gaillard et al., 2000 Macintire et al., 2001., Morar and Ramje, 2000), which showed that people who express fatalism are not likely to take-up an HIV test. Increasing education, particularly on available HIV treatment, positive living, self care and nutrition after a positive HIV diagnosis may reduce this perception and therefore increase VCT uptake.

Poor perception of the public health services linked to the VCT service may also be a reason for the low intake. A significant proportion of respondent responding to the structured questionnaire (39\%) indicated the service to be unsatisfactory while a few FGD participants expressed the concerns on such things as getting the wrong results, waiting for too long, unfriendly and rude counsellors, lack of privacy and lack of confidentiality. This poor perception may hinder them from taking up the test. 
Indeed findings from health systems research conducted in the same area indicate that poor perception of the health services in general was acting as a serious access barrier to health care (Audo and Njoroge, 2005).

Over the years the Kenyan public health system has natured a negative perception in the public due to limited availability as a result of shortages of skilled service providers, inadequate material resources, poor infrastructure and inadequate procurement and supply management systems (WHO/ UNAIDS/UNICEF 2007). Consequently this may be working against the VCT service utilization. In this light, therefore, delinking the service from the government health service may foster confidence among the community members and therefore more VCT utilization.

Some of the youths and young adults participants in the FGD expressed fear of what their parent would think if they found that they had gone for a test. This clearly suggest poor communication between the children and their parent which inturn hinders utilization of prevention services including HIV testing. In Kenya and indeed in many African countries, sexual matters are rarely discussed between children and parents due to cultural barriers. Recent prevention programs have included mass media campaigns targeted to adolescents and young adults warning of the risks for STDs and HIV and promoting condom use. While these approaches are important in prevention programming, multi-targeted approaches which include the whole family may also be important and yet, to date, have largely been ignored. It is widely recognized that families, and parents in particular, play a critical role in the socialization of children, preparing them to assume and perform their various roles in societies (Fox, 1981; Hepburn, 1983, Gecas and Seff, 1990). Orientating HIV education to target family could increase the VCT uptake.

\subsection{Study limitation conclusion and recommendation}

\subsubsection{Study Limitations}

While care was taken to collect objective data for this study there are some limitations that need to be taken into account in interpreting the study findings. First, the data were collected only in one geographic location, the Kenya's Rift valley province. The results might not be generalizable to other areas of Kenya. In addition, the study only surveyed two types of population groups, those who were already using the VCT facility (Client responding the structured questionnaire); and those reporting not to have taken the test and using a self help groups service facilitated by Faulu Kenya. These two groups could be systematically different from the other people living in the community and findings from other groups could be very different from the study findings. 
Self report bias may have occurred as the respondents were required to self report. Further, both the reluctance of the Key informant to be interviewed in depth and limitations on what they were willing to talk about in interviews hindered data collection. Finally, in Kenya discussion on sexual matters is sensitive; thus it is possible that some respondents reported HIV testing behaviours which they thought were socially desirable but that were not necessarily factual

\subsubsection{Conclusion}

Prompted by a low VCT uptake, despite high publicity and continued HIV infection, this study set to explore the dynamics of HIV testing among the rural and urban community of Nakuru district. The awareness regarding HIV and VCT among the community members is relatively high. Despite this however, there are still a significant proportion of people who hold misconceptions about the disease and more also the testing service. This may partially explain why people opted not to take the test. Further, a majority of the people want to take up the test but both social and health system barriers such as gender inequality, the cost of taking the service, service operational hours, accessibility; misconceptions about the disease among other barriers, make them not to utilize the service.

\subsubsection{Recommendations}

1. The study recommend testing more pro-active model of testing which could include mobile and home based testing to be piloted as if found to be working, they could help remove most of the barriers and therefore lead to an increased uptake.

2. Promotional activities targeting couples should be developed which may help purge the existing gender imbalance in the utilization.

3. Providing the service beyond the current normal working hours and weekends will enable those who have to work on a strict schedule during the week and weekend utilizes the service.

4. VCT service in the country is seen as part of public health facilities and therefore hindrances to the use of public health facilities are also hindrance to the use of VCT service.

5. Provide youth-friendly HIV voluntary counselling and testing centre to motivate youths to utilize the service. This could be for example, placing such things as indoor games facilities and video equipments. 


\section{References}

Abdool Karim, Q. A., Abdool Karim, S. S., Hoosen, M. C., \& Susser, M. (1998). Informed consent for HIV Testing in a South African Hospital: Is it Truly Informed and Truly Voluntary? American Journal of Public Health, 88, 637-640.

Admass M., Fitaw Y.(2006) Factors affecting acceptance of VCT among different professional and community groups in North and South Gondar Administrative zones, north west Ethiopia Ethiopian .journal of Health Development, 2006;20(1)

Allen, S., A. Serufilira, J. Bogaerts, P. Van de Perre, F. Nsengumuremyi, C. Lindan, M. Carael, W.Wolf, T. Coates, and S. Hulley. 1992. Confidential HIV testing and condompromotion in Africa: Impact on HIV and gonorrhea rates. Journal of the American Medical Association 268 (23): 3338-43.

Allen, S., A. Serufilira, V. Gruber, S. Kegeles, P. Van de Perre, M. Carael, and T. J. Coates. 1993. Pregnancy and contraceptive use among urban Rwandan women after HIV counselling and testing. American Journal of Public Health 83:705-10.

Allen, S., J. Tice, P. Van de Perre, A. Serufilira, E. Hudes, F. Nsengumuremyi, J. Bogaerts, C.Lindan, and S. Hulley. 1992. Effect of serotesting with counselling on condom use and seroconversion amongHIVdiscordant couples inAfrica. BritishMedical Journal 304:1605-9.

Arthur G., Nduba V., Forsythe S., Mutemi R., Odhiambo J., Gilks C. (2007) Behavior change in clients of health centre-based voluntary HIV counselling and testing services in Kenya STI online

Arthur G, Ngatia G, Rachier C, Mutemi R, Odhaimabo J, Gilks C: The role for government health centers in provision of same-day voluntary HIV counseling and testing in Kenya. J Acquired Immune Deficiency Syndrome 2005 , 40:329-35

Asingwire N (2004) Feasibility Study of the Mobile Van for Voluntary counselling and Testing for HIV / AIDS. Final report submitted to the Uganda Program for Human and Holistic Development (UPHOLD), Kampala, Uganda. Available at:http://www.uphold.jsi.com/Docs/Mobile_Van_VCT.pdf. Last accessed 29 March 2007.

Ayiga, N., Ntozi, J. P. M., Ahimbisibwe, F. E., Odwee, J., \& Okurut, F. N. (1999). Deaths, HIV testing and sexual behaviour change and its determinants in northern Uganda. In Resistance to Behavioural Change to Reduce HIV/AIDS infection, (pp. 6581). Kampala: Makerere University.

Baker, T.L. (1994), Doing Social Research (2nd Edn.), New York: McGraw-Hill Inc 
Balmer, D. H., Grinstead, O., Kihuho, F., Gregorich, S. E., Sweat, M. D., Kamenga, M. C. et al. (2000). Characteristics of individuals and couples seeking HIV-1 prevention services in Nairobi, Kenya: The voluntary HIV-1 counselling and Testing Efficacy study. AIDS and Behavior, 4, 15-23.

Baiden, F. , Remes, P., Baiden, R., Williams, J., Hodgson, A. Boelaert, M. et al. (2005) Voluntary counseling and HIV testing for pregnant women in the KassenaNankana district of northern Ghana: Is couple counseling the way forward?. AIDS Care 17 , pp. 648-657.

Beardsell, S. (1994). Should wider HIV testing be encouraged on the grounds of HIV prevention? AIDS care, 6, 5-19.

Beardsell, S. \& Coyle, A. (1996). A review of research on the nature and quality of HIV testing services: a proposal for process-based studies. Social Science and Medicine, 42, 733-743.

Beardsell, S. (1994). Should wider HIV testing be encouraged on the grounds of HIV prevention? AIDS care, 6, 5-19.

Bor, R., Miller, R., \& Salt, H. (1991). Uptake of HIV testing following counselling. Sexual and marital therapy, 6, 25-28.

Bitner, M.J. (1990), "Evaluating service encounters: the effects of physical surroundings and employee responses", Journal of Marketing, Vol. 54 pp.69-82.

Brimmer, W., Gillespie, I., \& Schomer, H. (1996). Profile of attendees for voluntary HIV testing-Western Province ATICC. South African Medical Journal, 86, 182.

Campbell Jr., C.H., Marum, M.E., Alwano-Edyegu, .M.G., Dillon, B.A., Moore, M. and Gumisiriza, E., (1997). The role of HIV counselling and testing in the developing world. AIDS Education and Prevention 9 Suppl. B, pp. 92-104.

Catania, J. A., Kegeles, S. M. \& Coates, T. J. (1990). Towards an understanding of risk behavior: An AIDS risk reduction model (ARRM). Health Education Quarterly, 17, 53-72.Njue

Carey, M.P., Morrison-Beedy, D., \& Johnson, B.T. (1997). The HIV-knowledge questionnaire: Development and evaluation of a reliable, valid, and practical selfadministered questionnaire. AIDS and Behavior, 1, 61-74.

Central Bureau of Statistics (CBS) [Kenya], Ministry of Health (MOH) [Kenya], and ORC Macro. 2004. Kenya Demographic and Health Survey 2003. Calverton, Maryland: CBS, MOH, and ORC Macro.

Cartoux, M., Msellati, P., Meda, N., Welffens-Ekra, C., Mandelbrot, L., Leroy, V. et al. (1998). Attitude of pregnant women towards HIV testing in Abidjan, Cote d' Ivoire and Bobo- Dioulasso, Burkina Faso. AIDS, 12, 2337-2344. 
Chesney, M. A., and Smith, A. W. (1999). Critical delays in HIV testing and care: The potential role of stigma. American Behavioral Scientist, 42, 1162-1174.

Creek, T., Ntumy, R., Mazhani, L., Moore, J., Smith, M., Han, G., et al. (2007). Factors associated with low early uptake of a national program to prevent mother to child transmission of HIV (PMTCT): Results of a survey of mother and providers, Botswana, 2003. AIDS and Behavior, 13(2), 356-364.

Crotty, M. (1998). The foundations of social research. London: Sage.

Coates, T. \& The Voluntary counselling and Testing Efficacy Study Group (2000).

Efficacy of voluntary HIV-1 counselling and testing in individuals and couples in Kenya, Tanzania, and Trinidad: A randomised trial. Lancet, 356, 103-112.

Coates TJ; Grinstead OA; Gregorich SE; Sweat MD; Kamenga MC; Sangiwa G; Balme (2000) Efficacy of voluntary HIV-1 counselling and testing in individuals and couple in Kenya Tanzania and Trinidad randomized controlled trial The Lancet; Jul 8, 2000; 356, 9224

Delva W., Mutunga L., Quaghebeur A., Temmerman M. (2006) Quality And Quantity of Antenatal HIV counselling in A PMTCT Programme in Mombassa, Kenya ;AIDS Care, April 2006; 18(3): 189-/193

Denzin \& Y. S. Lincoln (Eds.), Handbook of qualitative research (2nd ed,, pp. 10471065). Thousand Oaks, CA: Sage

Dey, I. (1993). Qualitative data analysis: a user-friendly guide for social scientists. London: Routledge

De Paoli, M.M., Manongi, R., \& Klepp, K.-I. (2004). Factors influencing acceptability of voluntary counselling and HIV-testing among pregnant women in Northern Tanzania. AIDS Care, 16(4), 411-425.

Dervin, B. (1997). Given a context by any other name: methodological tools for taming the unruly beast. In P. Vakkari, R. Savolainen \& B. Dervin, Brenda. (Eds.) Information seeking in context: proceedings of an international conference on research in information needs, seeking and use in different contexts, 14-16 August, 1996, Tampere, Finland. (pp. 13-38) London: Taylor Graham

Di Mauro D, Sexuality Research in the United States: An Assessment of the Social and Behavioural Sciences, New York

Forsythe S; Arthur G; Ngatia G; Mutemi R; Odhiambo J Gilks C . Assessing the cost and willingness to pay for voluntary HIV counselling and testing in Kenya Health Policy and Planning; Jun 2002; 17, 2

Eisenman, D. P., Cunningham, W. E., Zierler, S., Nakazono, T. T., and Shapiro, M. F. (2003). Effect of violence on utilization of services and access to care in persons with HIV. Journal of General Internal Medicine, 18, 125-127. 
Fisher, J. D. \& Fisher, W. A. (1992). Changing AIDS risk behavior. Psychological Bulletin, 111, 455-474 10.1037//0033-2909 .111.3.455.

Fylkesnes K \& Siziya S (2004) A randomized trial on acceptability of voluntary counselling and testing. Tropical Medicine and International Health 9, 566-572.

Fylkesnes, K., Haworth, A., Rosensvard, C., \& Kwapa, P. M. (1999). HIV counselling and testing: Overemphasizing high acceptance rates a threat to confidentiality and the right not to know. AIDS, 13, 2469-2474

Fox, G. (1981). The family's role in adolescent sexual behavior. In T. Ooms (Ed.), Teenage pregnancy in a family context (pp. 73-130). Philadelphia, PA: Temple University Press.

Fortenberry, J. D., McFarlane, M., Bleakley, A., Bull, S., Fishbein, M., Grimley, D. M., et al. (2002). Relationships of stigma and shame to gonorrhea and HIV screening. American Journal of Public Health, 92, 378-381.

Fortenberry JD, McFarlane M, Bleakley A, et al. Relationships of stigma and shame to gonorrhea and HIV screening. Am J Public Health. 2002;92:378-381

Gage, A. J. \& Ali, D. (2005). Factors associated with self-reported HIV testing among men in Uganda. AIDS Care, 17, 153-165.

Gecas, V., \& Seff, M. (1990). Families and adolescents: A review of the 1980s. Journal of Marriage and the Family, 52, 941-958.

Getachew B. Factors Associated with VCT Utilization in Guragae Zone, SNNPR, Ethiopia, April 2004. Thesis

Gibney, L., Wade, S., Madzime, S., \& Mbizvo, M. (1999). HIV testing practices of Zimbabwean physicians and their perspectives on the future use of rapid on-site tests. AIDS care 11, 603-673.

Gaillard P, Mellis R, and Mwayumba F et al. Vulnerability of women in the African setting: Lessons learnt for mother-tochild HIV prevention projects. AIDS $2002 ; 16(6)$ : 937-939

Global HIV Prevention Working Group. Bringing HIV Prevention to Scale: An Urgent Global Priority. Bill \& Melinda Gates Foundation and Henry J. Kaiser Family Foundation, June 2007

Global health council 2000, Measure DHS+ Indicators Database, (2000).

Hepburn, E. (1983). A three-level model of parent-daughter communication about sexual topics. Adolescence, 18(71), 523-534.

Herek, G.M. (1998) 'Bad Science in the Service of Stigma: A Critique of the Cameron Group's Survey Studies', pp. 223-55 in G.M. Herek (ed.) Stigma and 
Sexual Orientation: Understanding Prejudice against Lesbians, Gay Men, and Bisexuals.Thousand Oaks, CA: Sage.Cdc 2000

Higgins, D. L., Galavotti, C., O’reilly, K. R., Schnell, D. J., Moore, M., Rugg, D. L., \& Johnson, R. (1991). Evidence for the effects of HIV antibody counseling and testing on risk behaviors. Journal of the American Medical Association , 266, 24192429.

Holbrook, Morris B. and Kim P. Corfman (1985), "Quality and Value in the Consumption Experience: Phaedrus Rides Again," in Perceived Quality: How Consumers View Stores and Merchandise, eds. Jacob Jacoby and Jerry C. Olson, Lexington, MA: Lexington Books.

Yoder PS, Katahoire AR, Akol Z, Bunnell R \& Kaharuza F (2006) Home-Based HIV Testing and counselling in a Survey Context in Uganda. ORC Macro, Calverton, Maryland, USA.

Hutchinson, P. L., \& Mahlalela, X. Utilization of voluntary counselling and testing services in the Eastern Cape, South Africa. AIDS Care, July 2006; 18(5): 446-455

Ickovics, J. R., Morrill, A. C., Beren, S. E., Walsh, U., \& Rodin, J. (1994). Limited Effects of HIV Counselling and Testing for Women. JAMA, 272, 443-448.

Irwin, J. R., Jones, L. E. and Mundo, D. 'Risk perception and victim perception: The judgment of HIV cases', Journal of Behavioral Decision Making, 9 (1996), 1-22. Kim et al. 1997

Jereni BH, Muula AS. Availability of supplies and motivations for use of voluntary HIV counselling and testing services in Blantyre, Malawi BMC Health Services Research 2008 Jan 23; 8(1):17

Irungu, T., Varkey, P., Cha, S. and Patterson, J. (2008), HIV voluntary counselling and testing in Nakuru, Kenya: findings from a community survey. HIV Medicine, 9: $111-117$

Kamenga, M., R. W. Ryder, M. Jingu, N. Mbuyi, L. Mbu, F. Behets, C. Brown, and W. L. Heyward. 1991. Evidence of marked sexual behavior change associated with low HIV-1 seroconversion in 149 married couples with discordant HIV-1 serostatus: Experience at an HIV Counselling centre in Zaire. AIDS 5:61-67.

Kebaabetswe P, Bukonda NKZ, Ntseane D, Thior I. Male involvement in the prevention of mother to child transmission of HIV program in Botswana. First national HIV/AIDS/STI/other related infectious diseases research conference 2003; Gaborone, Botswana. Abstract TBT46-3.

Kiarie, J., Nduati, R., Koigi, K., Musia, J., \& John, G. (2000). HIV-1 testing in pregnancy: acceptability and correlates of return for test results. AIDS, 14, 1468-1470. 
Kipp, W., Kabagambe, W., \& Konde-lule, J. (2002). HIV counselling and testing in rural Uganda:Communities attitudes and perceptions towards an HIV counselling and tsting programme. AIDS care, 14, 699-706

Kiarie, J., Nduati, R., Koigi, K., Musia, J., \& John, G. (1999). HIV-1 testing in pregnancy: acceptability and correlates of return for test results. AIDS, 14, $1468 \_1470$.

Kim YM, Marangwanda C \& Kols A (1997) Quality of counselling of young clients in Zimbabwe. East African Medical Journal 74, 514-518.

Kawichai, S., Beyrer, C., Khamboonruang, C., Celentano, D. D.,Natpratan, C., Rungruengthanakit, K., and Nelson, K. E. (2004). HIV incidence and risk behaviours after voluntaryHIV counselling and testing (VCT) among adults aged 19- 35 years living in peri-urban communities around Chiang Mai City in northern Thailand, 1999. AIDS Care, 16, 21-35.

Ladner, J., Lerol, V., Msellati, P., Nyiraziraje, M., De Clercq, A., Van de Perre, P. et al. (1996). A cohort study of factors associated with failure to return for HIV post-test counselling in pregnant women: Kigali, Rwanda, 1992-1993. AIDS, 10, 69-75

Landis, S. E., Schoenbach V.J., \& Webber, D. J. (1992). Partner notification trial shows public health counsellors are more effective than the index HIV-infected patient in advising at risk partners. $N$ England Journal Med., 326, 101-106.

Lutalo, T., M. Kidugavu, and M.Wawer. 2000. Contraceptive use and HIV counselling and testing in rural Rakai district, SW Uganda. Abstract C246. Paper presented at the 13th International Conference on HIV/AIDS, Durban, South Africa.

Ma, W. , Detels, R. , Feng, Y., Wu, Z. , Shen, L. Li, Y. et al. (2007) Acceptance of and barriers to voluntary HIV counselling and testing among adults in Guizhou province, China. AIDS 21:Suppl. 8, pp. S129-S135

Machekano, R., Mcfarland, W., Mbizvo, M. T., Bassett, M. T., Katzenstein, D., \& Latif, A. S. (1998). Impact of HIV counselling testing on HIV seroconversion and reported STD incidence among male factory workers in Harare, Zimbabwe. Central African Journal of Medicine, 44, 98-101.

Macintyre, K., L. Brown and S. Sosler (2001). It's not what you know, but "who you knew": examining the relationship between behavior change and AIDS mortality in Africa. AIDS Education \& Prevention 13:160-174.

Maman, S., Mbwambo, J., Hogan, N.M., Kilonzo, G.P. \& Sweat, M. (2001). Women's barriers to HIV-1 testing and disclosure: challenges for HIV-1 voluntary counselling and testing. AIDS Care, 13, 595-603. 
Marum E, Barnaba A, Rayfield M, Campbell C, Dillon B, Fridlund C, Msowoya K; Whole blood rapid HIV tests and same day counseling results in Malawi. International Conference on AIDS International Conference on AIDS. $2000 \mathrm{Jul}$ 914; 13: abstract no. MoPeA2109.

Matovu, J. K., Kigozi, G., Nalugoda, F., Wabwire-Mangen, F., \& Gray, R. H. (2002). The Rakai Project counseling programme experience. Tropical Medicine and International Health, 7(12), 1064-1067

McNair, L.D., Carter, J.A.,\&Williams, M.K. (1998). Self-esteem, gender, and alcohol use: Relationships with HIV risk perception and behaviors in college students. Journal of Sex and Marital Therapy, 24, 29-36.

Mengesha A., Yohannis F Factors affecting acceptance of VCT among different professional and community groups in North and South Gondar Administrative zones, north west Ethiopia available online on http://ejhd.uib.no/ejhd-v20

Meursing, K. (1999). Barriers to sexual behavior change after an HIV diagnosis in sub-Saharan Africa. In Resistances to Behavioural change to Reduce HIV/AIDS infection (pp. 35-39). Melbourne.

MO Audo, A Ferguson, PK Njoroge (2005)Quality of health care and its effects in the utilisation of maternal and child health services in Kenya. East African Medical Journal Vol. 82(11) : 547-553

Moss W, Bentley M, Maman S, Ayuko D, Egessah O, Sweat M, Nyarang'o P, Zenilman J, Chemtai A, Halsey N: Foundations for effective strategies to control sexually transmitted infections: voices from rural Kenya. AIDS Care 1999 , 11:95-113

Morar, N.S., \& Ramjee, G. (2000). Impact of voluntary HIV counselling and testing among sex workers. Paper delivered at the XIIIth International AIDS conference, Durban.Irwin

Morin, S. F. , Khumalo-Sakutukwa, G. , Charlebois, E. D. , Routh, J. , Fritz, K. Lane, T. et al. (2006) Removing barriers to knowing HIV status: Same-day mobile HIV testing in Zimbabwe. Journal of Acquired Immune Deficiency Syndromes 41:2 , pp. 218-224.

Muller O, Sarangbin S, Ruxrungtham K, Sittitrai W \& Phanuphak P (1995) Sexual risk behaviour reduction associated with voluntary HIV counselling and testing in HIV infected patients in Thailand. AIDS Care 7, 567-572.

Muller, O., Barugahare, L., Schwartlander, B., Byaruhanga, E., Kataaha, P., Kyeyune, D. et al. (1992). HIV prevalence, attitudes and behaviour in clients of a confidential HIV testing and counselling centre in Uganda. AIDS, 6, 869_/879.

Mpairwe H, Muhangi L, Namujju P, Kisitu A, Tumusiime A, Muwanga M, Whitworth J, Onyango S, Biryahwaho B, Elliot A. 2005. "HIV risk perception and prevalence in a program for prevention of mother-to-child transmission: Comparison 
of women who accept voluntary counseling and testing and those tested anonymously." Journal of Acquired Immune Deficiency Syndrome. 39 (3): 354- 358.

National AIDS and STI Control Programme, Ministry of Health, Kenya. July 2008. Kenya AIDS Indicator Survey 2007: Preliminary Report. Nairobi, Kenya. 07'

National AIDS Control Council, Office of the President, Kenya (2010) UNGASS 2010 Country Report for Kenya. NACC, Nairobi.

Ndola Prata, Leo Morris, Elizio Mazive, Farnaz Vahidnia, Mark StehrSource: International Family Planning Perspectives, Vol. 32, No. 4 (Dec., 2006), pp. 192-200

Njue, C et al (2009) "If you don't abstain, you will die of AIDS": AIDS education in Kenyan public schools', AIDS Education and Prevention, 2009 April;21(2):169-79.

Olewe TM, Wanyungu JO. and Muindi AM, 2008. Characteristics of clients seeking voluntary Counselling and testing (VCT) services in Nairobi, Kenya. Journal of Applied Biosciences 12: 671 - 680.

Okonkwo, K.C., Reich, K., Alabi, A.I., Umeike, N., \& Nachman, S.A. (2007). An evaluation of awareness: Attitudes and beliefs of pregnant Nigerian women toward voluntary counselling and testing for HIV. AIDS Patient Care and STDs, 21(4), 252260.

O'Reilly, K.R., Medley, A., Dennison, J., Schmid, G.P., \& Sweat, M.D. (2003). Systematic review of the impact of abstinence-only programmes on risk behaviour in developing countries. The Cochrane Database of Systematic Reviews, 1.

Parasuraman, A., Zeithaml, V.A., Berry, L.L. (1994), "Alternative scales for measuring service quality: a comparative assessment based on psychometric and diagnostic criteria", Journal of Retailing, Vol. 70 pp.201-30.

Perez F, Zvandaziva C, Engelsmann B \& Dabis F (2006) Acceptability of routine HIV testing ("opt-out") in antenatal services in two rural districts of Zimbabwe. Journal of Acquired Immune Deficiency Syndromes 41, 514-520.

Pool, R., Nyanzi, S., Whitworth, J. (2001). Breast feeding practices and attitudes relevant to the vertical transmission of HIV in rural south-west Uganda. Annals of Tropical Paediatrics 21: 119-125.

Sarker, M., Milkowski, A., Slanger, T., Gondos, A., Sanou, A., Kouyate, B., et al. (2005). The role of HIV-related knowledge and ethnicity in determining HIV risk perception and willingness to undergo HIV testing among rural women in Burkina Faso. AIDS and Behavior, 9(2), 243-249 
Sahly, Kassa, Agonafer, Tsegaye, De Wit, Gebremarium, Doorly, Spijkerman, Yeneneh, Coutinho \& Fontanet Al. Sexual behaviour, perception of risk of HIV infection and factors associated with HIV post -test couselling in Ethiopian. AIDS, 1999 Jul 9;13(10):1263-72

Shisana O, Zungu-Dirwayi N, Toefy Y, Simbayi LC, Malik S, Zuma K. Marital status and risk of HIV infection in South Africa. S Afr Med J. 2004;94:537-543.

Sherr L, Lopman B, Kakowa M et al. (2007) Voluntary counselling and testing: uptake, impact on sexual behaviour, and HIV incidence in a rural Zimbabwean cohort. AIDS 21, 851-860.

Sibthorpe, B 1992. The Social Construction of Sexual Relationships as a Determinant of HIV Risk Perception and Condom Use among Injection Drug Users. Medical Anthropology Quarterly VL - 6 IS - 3 pg 1548-1387

Stall, R., Hoff, C., Coates, T. J., Paul, J., Phillips, K. A., Ekstrand, M., et al. (1996). Decisions to get HIV tested and to accept antiretroviral therapies among gay/bisexual men: Implications for secondary prevention efforts. Journal of Acquired Immune Deficiency Syndrome, 11, 151-160.

Stein, J.A., \& Nyamathia, A. (2000). Gender differences in behavioral and psychosocial predictors of HIV testing and return for test results in a high-risk population. AIDS Care, 12(3), 343-356.

Strode, A. Scaling up HIV testing in resource constrained settings: Debates on the role of VCT and Routine 'Opt-in or Opt-out'HIV Testing, Southern African Journal of HIV Medicine Vol. 6 (3) 2005: pp. 45-48

Rosenberg, K.M. and Daly, H.B. (1993), Foundations of Behavioural Research: A Basic Question Approach, Fort Worth/London: Harcourt Brace College Publishers. p 182-184.

Temmerman, M. et al. 1995. "The right not to know HIV test results," The Lancet 345: 969-970.

Thior I, Gabaitiri L, Grimes J, et al. Voluntary counseling and testing among postpartum women in Botswana. Patient Educ Couns. 2007;65(3):296-302.

Tools for evaluating HIV voluntary counselling and testing. UNAIDS Best Practice Collection Key Material, Geneva, UNAIDS, 1999

Van der Straten, A., R. King, O. Grinstead, A. Serufilira, and S. Allen. 1995. Couple communication, sexual coercion and HIV risk reduction in Kigali, Rwanda. AIDS 9 (8): 935-44. 
Van Rooyen, H. \& Wood, G. (1997). The importance of HIV test counselling. Occupational Health Southern Africa, 3, 23.

Voluntary HIV-1 counselling and Testing Efficacy Study Group. 2000a. Efficacy of voluntary HIV-1 counselling and testing in individuals and couples in Kenya, the United Republic of Tanzania and Trinidad: A randomized trial. Lancet 356:103-12.

Wilkinson, D. \& Wilkinson, N. (2001). Acceptability of prenatal, voluntary HIV counselling and testing and interventions to reduce mother-to-child transmission of HIV infection in rural South Africa. South African Medical Journal, 91, 48-49.

Williamson K. Research methods for students and professionals: Information management and systems (2nd ed.), Centre for Information Studies Charles Sturt University, Wagga Wagga, NSW (2002

Wilson, T., Levinson, R. A., Jaccard, J., Minkoff, H., \& Endias, R. (1996). Testing for HIV and other sexually Transmitted Diseases: Implications for risk behavior in women. Health Psychology, 15, 252-260.

Wu Z, Sullivan SG, Wang Y, Rotheram-Borus MJ, Detels R. Evolution of China's response to HIV/AIDS. Lancet. 2007;369:679-90 


\section{Appendices}

Appendix 1: Information sheets

TE WHARE WĀNANGA O TE U POKO O TE IKA A MĀUI

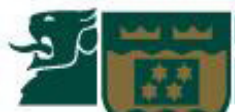

Information Sheet

\section{DETERMINING THE DYNAMICS OF HIV VOLUNTARY COUNSELLING AND TESTING UPTAKE AMONG THE RURAL AND URBAN COMMUNITIES OF NAKURU DISTRICT, KENYA.}

\section{Focus Group Discussion}

I am a graduate student in Applied Social Science Research, Victoria University of Wellington, New Zealand. As part of this degree I am undertaking a research project leading to a thesis. This project examines factors that determine Voluntary Testing and counselling (VCT) uptake. The university requires that ethics approval be obtained for research involving human participants.

I am inviting men and women who have not used the service to participate in focus groups discussions. It will take an average of one hour. During the discussion it is important that you provide your frank opinion; there is no right or wrong opinion. A person can only withdraw from the discussion group before it starts. Just let me know at the time.

Either myself or my research assistant will be writing down what we discuss and the discussion will be recorded on tape. Please note that the recorder is just to help me to keep accurate record of our proceedings. The recorded proceedings will form the basis of my research project and will be put into a written report on an anonymous basis. It will not be possible for you to be identified personally. Only group responses will be presented in this report. You will be asked not to talk about the focus group discussion outside of the recording session.

All the recorded material will be kept confidential with no other person besides me and my supervisor having access to them. The thesis will be submitted for marking at the School of Social and Cultural studies and deposited at the university library. It is intended that one or more articles will be submitted for publication in scholarly 
journals. The recorded proceedings will be wiped out after five years after the end of the project.

If you have any question or would like to receive further information about the project, please contact me at the Health of Migrant Population AMPATH Centre, Eldoret, or call me on 0721573814 or my thesis supervisor Prof. Kevin Dew, Tel $+6444635291$ 
Appendix 3: Consent to participate in the research Study for Focus Group

Discussion

TE WHARE WĀNANGA O TE ŨPOKO O TE IKA A MĀUI

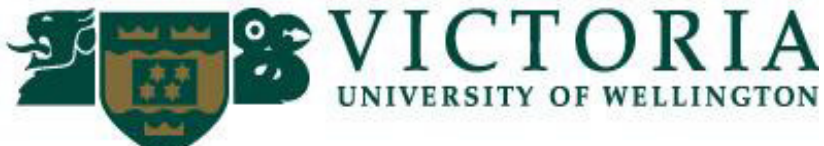

\section{DETERMINING THE DYNAMICS OF HIV VOLUNTARY COUNSELLING AND TESTING UPTAKE AMONG THE RURAL AND URBAN COMMUNITIES OF NAKURU DISTRICT, KENYA.}

\section{Focus Group Discussion}

I have been given and have understood an explanation of this research project. I have had an opportunity to ask questions and have them answered to my satisfaction.

I understand that I can only withdraw from this project before the start of the discussion.

I understand that any information I provide will be kept confidential to the researcher, the supervisor and the person who transcribes the tape recordings of our interview, the published results will not use my name, and that no opinions will be attributed to me in any way that will identify me.

$\square \quad$ I understand that the tape recording of the interview will be electronically wiped five years upon completion of the project.

$\square \quad$ I hereby give permission to Joseph Muchiri to use, distribute or publish the information that I provide for the purposes of the study in any way that Joseph Muchiri deems fit without any further recourse or reference to me.

Sign:

Date: 
Information Sheet

\section{DETERMINING THE DYNAMICS OF HIV VOLUNTARY COUNSELLING AND TESTING UPTAKE AMONG THE RURAL AND URBAN COMMUNITIES OF NAKURU DISTRICT, KENYA.}

\section{In-depth Interviews}

I am a graduate student in Applied Social Science Research, Victoria University of Wellington, New Zealand.

As part of this degree I am undertaking a research project leading to thesis. This examines the factors that determine Voluntary Testing and counselling (VCT) uptake. The university requires that ethics approval be obtained for research involving human participants.

I am inviting VCT counsellors and project Managers involved in service delivery to participate in this study. If you agree to participate, an interview lasting approximately 30 minutes will be undertaken with you. During the interview it is important that you express your frank opinion as there no right or wrong opinion. Should you feel like withdrawing you may do so up to one month from the interview and any data collected will be destroyed.

During the interview, I will be writing down what we discuss and will record the discussion. Please note that the recorder is just to help me to keep accurate records of our conversation. The transcription of the interview will form the basis of my research project and will be put into a written report on an anonymous basis. That is, you will not be personally identified as Counsellors responses will be presented in an aggregated form. All the recorded material will be kept confidential and secure and no other person besides my supervisor and myself will have access to the data. The thesis will be submitted for marking at the School of Social and Cultural Studies and be deposited in the university library. It is intended that one or more articles will be 
submitted for publication in scholarly journals. The recorded proceedings will be wiped out after five years after the end of the project

If you have any questions or would like to receive further information about the project, please contact me at the Health of Migrant Population AMPATH Centre, Eldoret, or call me on 0721573814 or my thesis supervisor Prof. Kevin Dew, Tel +6444635291 
Appendix 3: Consent to participate in the research Study for In-depth interviews

\title{
DETERMINING THE DYNAMICS OF HIV VOLUNTARY COUNSELLING AND TESTING UPTAKE AMONG THE RURAL AND URBAN COMMUNITIES OF NAKURU DISTRICT, KENYA.
}

\begin{abstract}
In-depth interviews
I have been given and have understood an explanation of this research project. I have had an opportunity to ask questions and have them answered to my satisfaction.
\end{abstract}

I understand that I may withdraw myself (or any information I have provided) from this project up until one month from the interview at which time any data collected will be destroyed

I understand that any information I provide will be kept confidential to the researcher, the supervisor and the person who transcribes the tape recordings of our interview, the published results will not use my name, and that no opinions will be attributed to me in any way that will identify me.

$\square \quad$ I understand that the tape recording of the interview will be electronically wiped five years upon completion of the project.

$\square \quad$ I hereby give permission to Joseph Muchiri to use, distribute or publish the information that I provide for the purposes of the study in any way that Joseph Muchiri deems fit without any further recourse or reference to me.

Sign:

Date: 


\section{Appendix 4: Information sheet for the questionnaire}

TE WHARE WĀNANGA O TE ŨPOKO O TE IKA A MĀUI

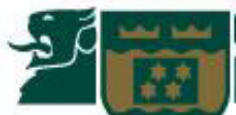

\section{DETERMINING THE DYNAMICS OF HIV VOLUNTARY COUNSELLING \\ AND TESTING UPTAKE AMONG THE RURAL AND URBAN \\ COMMUNITIES OF NAKURU DISTRICT, KENYA.}

\section{Survey questionnaire}

I am a graduate student in Applied Social Science Research, Victoria University of Wellington. As part of this degree I am undertaking a research project leading to thesis. The project I am undertaking is examining the factors that determine Voluntary Testing and counselling (VCT) uptake. Ethical approval has been obtained to conduct this research from Victoria University of Wellington and I am inviting men and women who are using the VCT service to participate in the study. You will be asked to complete a questionnaire which will take approximately 30 minutes to complete. Completion of the questionnaire implies consent to participate in the research.

It is important that you complete the questionnaire with complete honesty; there is no right or wrong answer. All responses collected will be put into a written report on an anonymous basis. It will not be possible for you to be identified personally. All the data collected will be kept secure and no other person besides me and my supervisor will have access to the completed questionnaire. The thesis will be submitted for marking at the School of Social and Cultural studies and deposited at the university library. It is intended that one or more articles will be submitted for publication in scholarly journals. The questionnaires will be destroyed five years after the end of the project.

If you have any questions or would like to receive further information about the project, please contact me at the Health of Migrant Population AMPATH Centre, Eldoret, or call me on 0721573 814, or my thesis supervisor Prof. Kevin Dew, Tel +6444635291 .

Thank you for participating in this research Joseph M. Muchiri 
Appendix 7: VCT Client Exit Questionnaire

Title: Determining the dynamics of HIV Voluntary Counselling and testing

(VCT) uptake among the rural and urban communities of Nakuru district,

Kenyan.

The following questionnaire is designed to investigate factors that affect VCT utilization among urban and rural communities. The questionnaire takes approximately 30 minutes to complete. Please feel free to express your frank opinion on all issues.

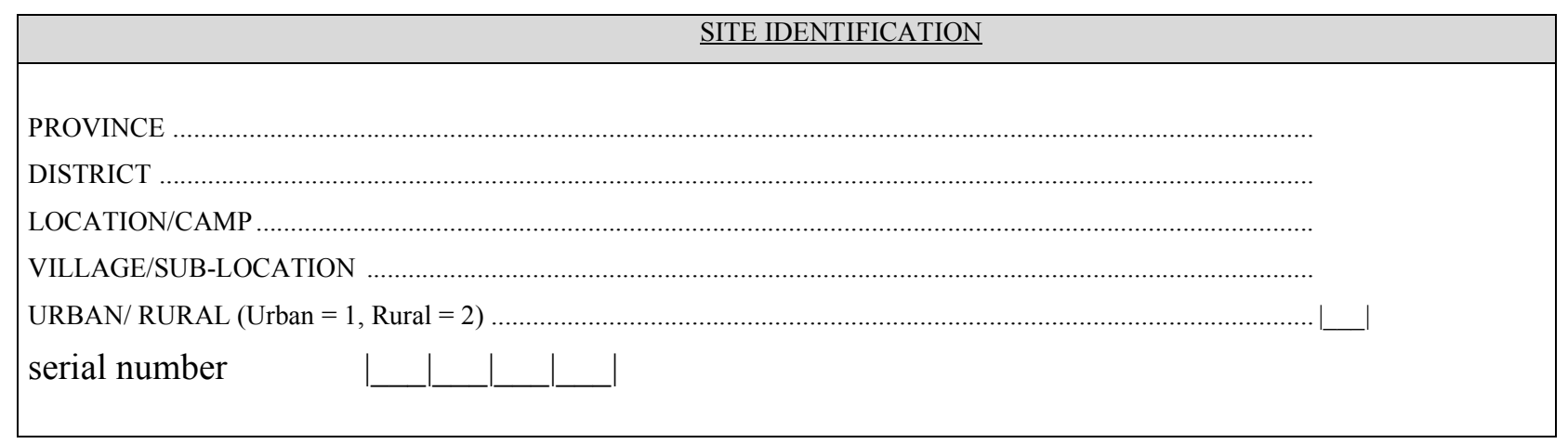




\begin{tabular}{|c|c|c|c|}
\hline NO. & QUESTIONS & ANSWERS & SKIP \\
\hline \multicolumn{4}{|c|}{ A. Socio-demographic } \\
\hline 1. & Gender & $\begin{array}{l}1=\text { Male } \\
2=\text { Female }\end{array}$ & \\
\hline 2. & How old are you? & Record number of years & \\
\hline 3. & What is your religion? & $\begin{array}{l}1=\text { Catholic } \\
2=\text { Protestant } \\
3=\text { Muslim } \\
4=\text { African Traditional Religion } \\
5=\text { None }\end{array}$ & \\
\hline 4. & What is the highest level of schooling have you completed? & $\begin{array}{l}0=\text { Have never attended school } \\
1=\text { Did not complete primary education } \\
2=\text { Primary } \\
3 \text { = Secondary } \\
4=\text { Post secondary school (including college, university, } \\
\text { other diploma) }\end{array}$ & \\
\hline 5. & What is your current relationship status? & $\begin{array}{l}1 \text { = Currently married } \\
2=\text { living with a man/woman as if we are married } \\
3=\text { Never married } \\
4=\text { Divorced } \\
5=\text { Widow } / \text { Widower } \\
6=\text { Separated }\end{array}$ & \\
\hline 6. & Where are you currently living? & $\begin{array}{l}\text { District } \\
\text { Division } \\
\text { Location } \\
\text { Sub-location } \\
\text { Village }\end{array}$ & \\
\hline 7. & What do you do for living? & & \\
\hline 8. & $\begin{array}{l}\text { If currently in a relationship, what do your partner /spouses do for } \\
\text { living? }\end{array}$ & & \\
\hline \multicolumn{4}{|c|}{ Knowledge on HIV infection, transmission and prevention } \\
\hline 9. & $\begin{array}{l}\text { Now I would like to talk about something else. } \\
\text { Have you ever heard of an illness called AIDS? }\end{array}$ & $\begin{array}{l}0=\text { No } \\
1=\text { Yes }\end{array}$ & $\begin{array}{l}\text { If no Go to } \\
\text { the end }\end{array}$ \\
\hline
\end{tabular}




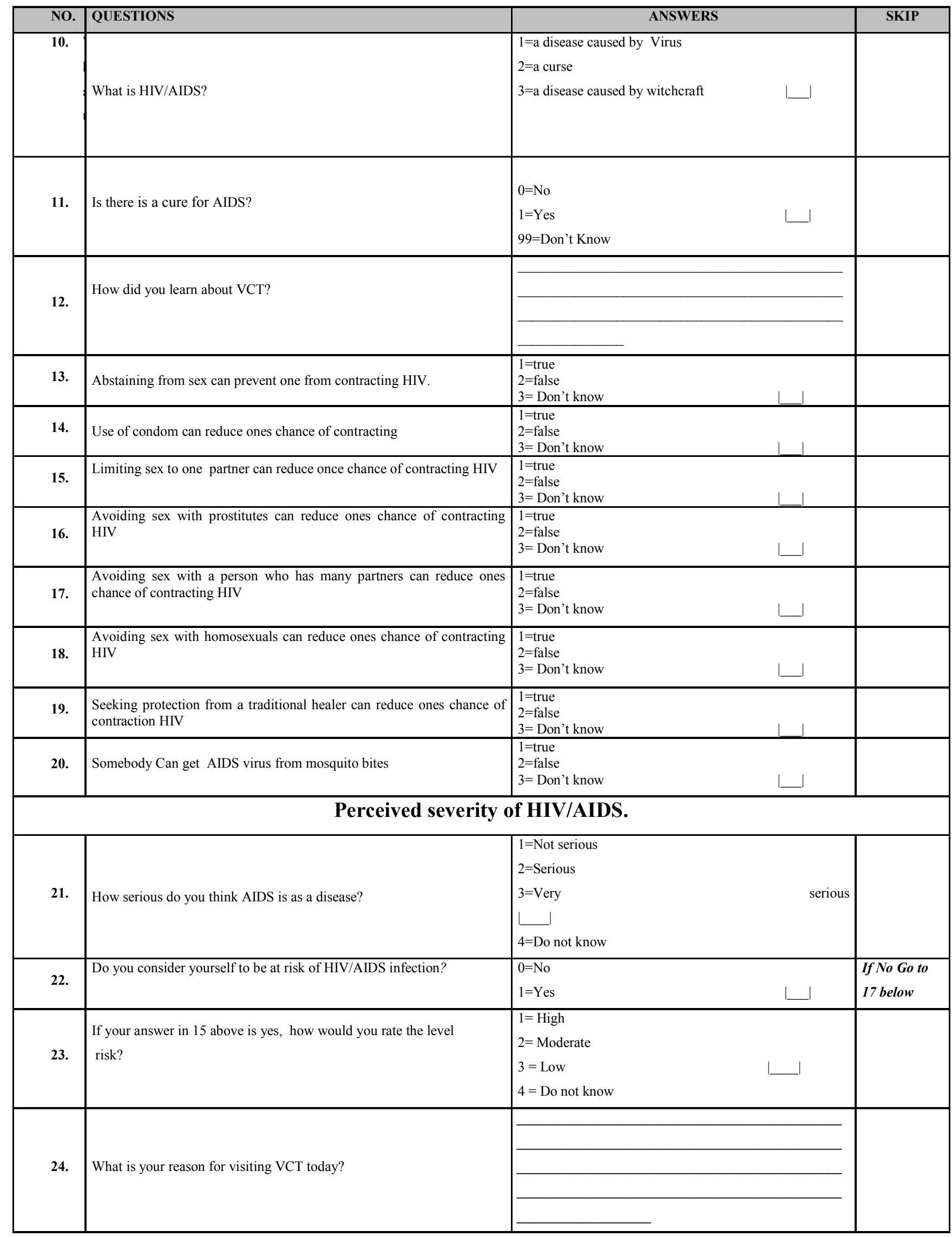




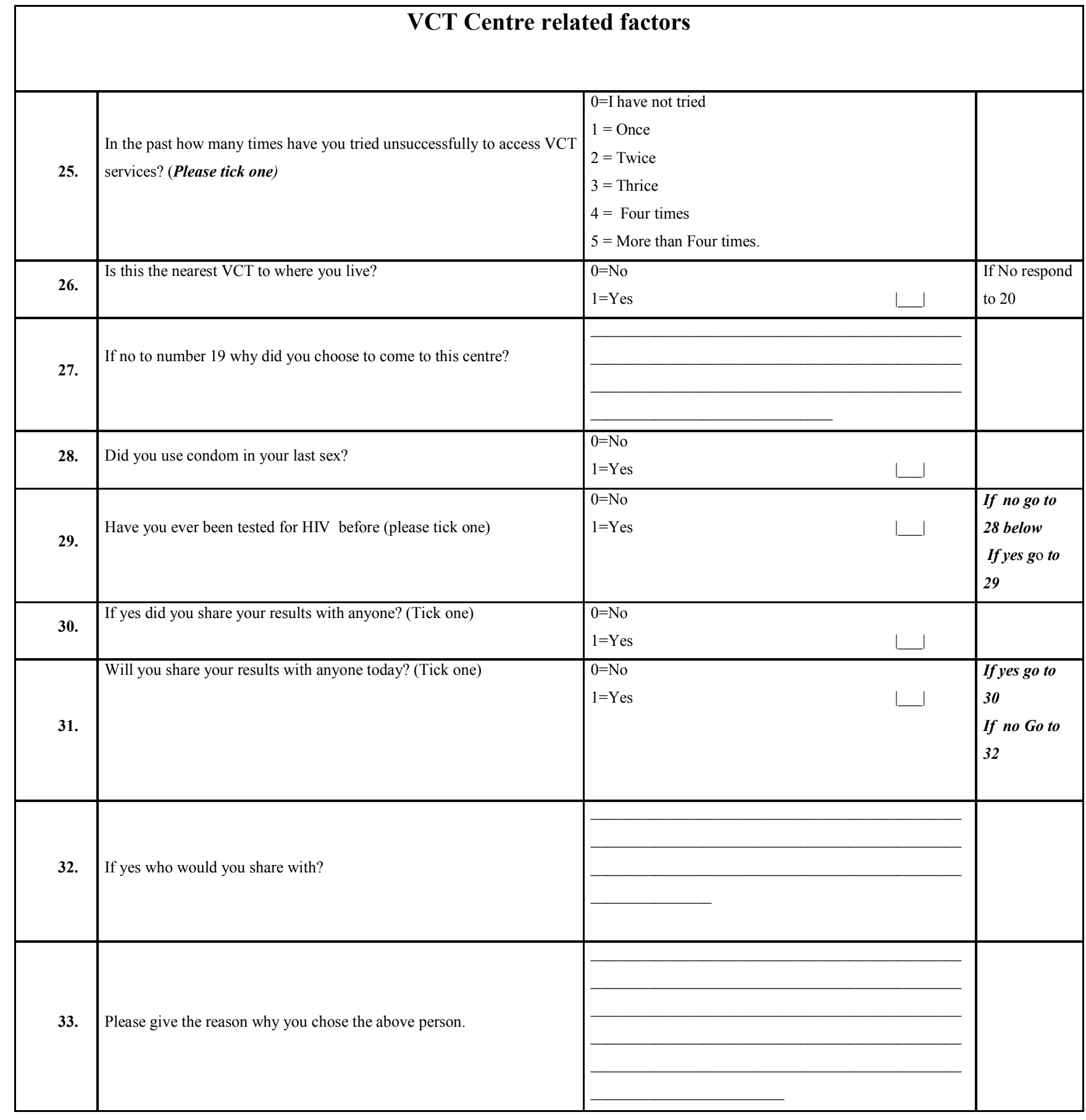




\begin{tabular}{|c|c|c|}
\hline 34. & If no to No .29 above, why not (Please tick as many as apply) & $\begin{array}{l}1=\text { Fear of rejection } \\
2=\text { Fear of separation } \\
3=\text { Fear of blame for positive test result } \\
4=\text { Other } \\
\text { specify }\end{array}$ \\
\hline 35. & $\begin{array}{l}\text { Are you satisfied with the way your results were handled? (Please Tick } \\
\text { one) }\end{array}$ & $\begin{array}{l}0=\text { No } \\
1=\text { Yes }\end{array}$ \\
\hline \multicolumn{3}{|c|}{ Opinion statements on HIV testing (Please check one that apply) } \\
\hline 36. & $\begin{array}{l}\text { People who test HIV positive are likely to be treated differently or } \\
\text { discriminated against. (Tick one) }\end{array}$ & $\begin{array}{l}\text { 1=Strongly Agree } \\
\text { 2=Agree } \\
3=\text { Disagree } \\
4=\text { Strongly disagree } \\
\text { 5=Don't know } \\
\end{array}$ \\
\hline 37. & $\begin{array}{l}\text { Would you be willing to take care of a family member with AIDS (Tick } \\
\text { one) }\end{array}$ & $\begin{array}{l}1=\text { Willing } \\
2=\text { Not willing } \\
3=\text { not sure }\end{array}$ \\
\hline 38. & Did you have to seek permission from anyone? (Tick one) & $\begin{array}{l}0=\text { No } \\
1=\text { Yes }\end{array}$ \\
\hline 39. & If your answer is yes please specify & $\begin{array}{l}\text { Please } \\
\text { specify } \ldots \ldots \ldots \ldots \ldots \ldots \ldots \ldots \\
\ldots \ldots \ldots \ldots \ldots \ldots\end{array}$ \\
\hline \multicolumn{3}{|c|}{ Quality of Counselling } \\
\hline 40. & Did you have enough time with the counsellor? (Tick one) & $\begin{array}{l}1=\text { Too long } \\
2=\text { Too short } \\
3=\text { just right } \\
\end{array}$ \\
\hline 41. & Do you hope to benefit from knowing your sero-status? (Tick one) & $\begin{array}{l}0=\text { No } \\
1=\text { Yes }\end{array}$ \\
\hline 42. & $\begin{array}{l}\text { Did you feel your issues would remain safe with the Counsellor? (Tick } \\
\text { one) }\end{array}$ & $\begin{array}{l}0=\mathrm{No} \\
1=\text { Yes }\end{array}$ \\
\hline 43. & Did you have privacy during counselling? (Tick one) & $\begin{array}{l}0=\text { No } \\
1=\text { Yes }\end{array}$ \\
\hline 44. & Was the counselling room at a convenient place? (Tick one) & $\begin{array}{l}0=\mathrm{No} \\
1=\mathrm{Yes}\end{array}$ \\
\hline 45. & How was the attitude of the staff? (Tick one) & $\begin{array}{l}1=\text { Good } \\
2=\text { Satisfactory } \\
3=\text { Bad }\end{array}$ \\
\hline
\end{tabular}


This is the end of the questionnaire. Thank you for taking your time to respond to this questionnaire, the information that you have provided will go a long way in helping improve VCT services in the country. 


\section{Appendix 8: In-depth Interview Guide for Counsellors}

\section{Title: Determining the dynamics of voluntary Counselling and testing uptake among the rural and urban communities of Nakuru district, Kenyan.}

1. For how long have you been counselling?

2. Do VCT counselling require any specific training ?

3. Could you please describe the procedure that a client has to go through when they come for the test?

4. Are you seeing the optimal number of clients per day?

5. What do you think are the factors influencing clients to come for VCT?

6. What are the major concerns that your clients usually have when they come for the test?

7. What are the major factors that may affect your ability to see clients in terms of numbers?

8. Do you refer clients for additional care services?

9. Do you think that clients are equipped with information that will enable them deal with stigma associated with HIV testing?

10. How would you describe you clientele in terms of age marital status?

11. Do you have any recommendation that could help improve the service? 
Appendix 9: In-depth Interview Guide for VCT Managers

Title: Determining the dynamics of voluntary Counselling and testing uptake among the rural and urban communities of Nakuru district, Kenyan.

1. Do you have any specific training on VCT management

2. What are the main problems do you encounter in running the service?

3. Do you have a consistent supply of test kits and reagents?

4. In your opinion, what could be done to enable more clients to access VCT services?

5. Do you think your site is well placed for the convenience of the clients?

6. How would you rate the quality of the services at your site?

7. Lastly, if you were given a chance to restart the service all over again are there things that you would want done differently? 


\section{Appendix 10: Focus Groups Discussion Guide}

\section{Focus group discussion tool}

1. Do people your age talk about HIV/AIDS?

2. Are you or people like you worried about the risk of contracting HIV/AIDS?

3. Do you think that many people your age want to know their HIV status?

4. Do you think that, in general, HIV positive people discuss their status?

5. Do you know of any places that offer HIV counselling in your area or elsewhere?

6. What do you see as being the benefits of HIV counselling and testing services offered at VCT centres?

7. What kind of people do you think would be most interested in these types of counselling and testing services offered at VCT centres?

8. What would hinder you or people like you from making use of VCT services?

9. What would motivate or encourage you to go for HIV testing?

10. Do you think a person might change his or her behaviour, if he or she found out that they were HIV positive after taking an HIV test?

11. Do you think a person might change his or her behaviour, if he or she found out that he or she were HIV negative after taking an HIV test?

12. How could people like you be made aware of VCT?

13. What kind of information would you or people like you want to know about Voluntary counselling and Testing (VCT)?

14. What types of services would you expect to get at a VCT centre?

15. How would you like to be served at a VCT centre? 